\title{
Signature of the coastal circulation variability in altimetric data in the southern Bay of Biscay during winter and fall 2004
}

\author{
G. Herbert ${ }^{\mathrm{a}, \mathrm{c}, *}$, N. Ayoub ${ }^{\mathrm{a}, \mathrm{c}}$, P. Marsaleix ${ }^{\mathrm{b}, \mathrm{c}}$, F. $_{\text {Lyard }}^{\mathrm{a}, \mathrm{c}}$ \\ a CNRS, LEGOS, 14 Av. Édouard Belin, F-31400 Toulouse, France \\ b CNRS, LA, 14 Av. Édouard Belin, F-31400 Toulouse, France \\ c Université de Toulouse, UPS (OMP), LEGOS, F-31400 Toulouse, France
}

The upper circulation in the southern Bay of Biscay is analysed over winter and fall 2004 using a coastal altimetric dataset, moorings, sea surface temperature (SST) observations and a regional simulation from the SYMPHONIE model. The aim is to determine whether altimetric data can detect occurrences of a slope current (the Iberian Poleward Current, IPC). We first analyse in situ and SST data. The results show pulses of a warm surface poleward flow (IPC) limited to the westernmost part of the northern Spanish coast. Along-track TOPEX/Poseidon and Jason-1 data are analysed over three 'events' (Jan., Feb., and Oct. 2004). Altimetric data can depict the main pulses. They provide some information on their spatial variability but the present in situ dataset is not dense enough to assess this information. Local inconsistencies between neighbouring tracks may be related to uncertainties in altimetric corrections. The simulated fields are consistent with the in situ observations. They allow us to better understand the IPC subsurface properties and its signature in altimetric data. The ability of altimetry to monitor IPC pulses under any atmospheric conditions or when the SST signature is weak makes it an essential component for the IPC observing system in addition to satellite SST and moorings data.

\section{Introduction}

The circulation in the southern part of the Bay of Biscay (North-East Atlantic) results from the complex combination of currents over the shelf and slope, characterised by a strong baroclinicity over the slope, mesoscale eddies further offshore, local upwellings and internal tide generation in the west (Pingree and Le Cann, 1989, 1990, 1992; Van Haken, 2002; Pichon and Corréard, 2006). It also shows a large seasonal and interannual variability due to the development of the Iberian Poleward Current (IPC) in late fall and winter along the western Iberian coast (Haynes and Barton, 1990; Frouin et al., 1990). From in situ and satellite infrared measurements, Frouin et al. (1990) describe a poleward flow of warm and salty waters over the upper slope and outer continental shelf west of Iberia during the winter of 1983-1984. This current, 25$40 \mathrm{~km}$ wide, is characterised by velocities ranging from 0.2 to $0.3 \mathrm{~m} / \mathrm{s}$ and waters typically $\sim 0.5^{\circ}$ to $1.5^{\circ} \mathrm{C}$ warmer than the surrounding ones. Frouin et al. (1990) describe it as a quasi-geostrophic $200 \mathrm{~m}$ deep flow, but, as reported by Coelho et al. (1999), other authors suggest that the IPC system extends deeper. In this paper, we will refer to IPC as the surface component of this eastern current system. Similar poleward flows have been described in other eastern boundary regions, such as the Leeuwin

\footnotetext{
* Corresponding author. Tel.: +33 5 61333046; fax: +33 561253205

E-mail addresses: gaelle.herbert@legos.obs-mip.fr (G. Herbert), nadia.ayoub@legos.obs-mip.fr (N. Ayoub), patrick.marsaleix@aero.obs-mip.fr (P. Marsaleix), florent.lyard@legos.obs-mip.fr (F. Lyard).
}

current off the west coast of Australia or in the Californian Current System. In some winters, the IPC has been observed to progress eastward along the northern Spanish coast, with typical speeds of 0.10 to $0.2 \mathrm{~m} / \mathrm{s}$, advecting warm water masses, that results in sea surface temperature (SST) differences between the shelf and the open ocean of $0.5-1{ }^{\circ} \mathrm{C}$ (Garcia-Soto et al., 2002; Le Cann and Serpette, 2009). The IPC incursion into the Bay of Biscay has been referred to as 'Navidad event' by Pingree and Le Cann (1992) as it usually occurs in early winter.

Several driving mechanisms can contribute to the establishment of the IPC (see Coelho et al., 1999, for a clear summary). Thermohaline forcing is thought of as the primary driving mechanism: the large-scale meridional density gradient in the north-east Atlantic leads to a weak eastward flow towards the eastern boundary that in turn forces a coastal downwelling and by geostrophic adjustment a poleward alongshore flow (e.g. Peliz et al., 2003). The bathymetry is shown to partially constrain the flow over the upper slope via JEBAR (Joint Effect of Baroclinicity and Relief) (Huthnance, 1984). Pingree and Le Cann (1990) show that the eastern slope boundary current can be driven by realistic distributions of seawater density and partially wind driven, consistently with a prevailing wind from west-southwest in fall-winter. The latter drives water accumulation at the Portuguese coast due to the Ekman effect that in turn generates a northward current. Another possible forcing is the positive wind stress curl west of Iberia and the associated poleward Sverdrup transport (Haynes and Barton, 1990; Le Cann and Serpette, 2009). The mechanisms of generation of the IPC are not necessarily the same as those responsible for its propagation along the 
northern Spanish coast. Local wind stress there is expected to favour Navidad events when directed towards the east (e.g. Le Cann and Serpette, 2009). In summary, the complexity of the existing processes that account for the IPC is such that the specific role of each forcing and the way they interact are not yet well understood. Moreover, the influence of the atmospheric time scales of variability has been little investigated (see Otero and Ruiz-Villarreal, 2008; Otero et al., 2008, for studies in the northwest Iberia area). Torres and Barton (2006) note that the northward winds west of Iberia are highly variable and may impact the IPC variability at short-time scales.

Because of their conspicuous SST signature and their potential impact on the local biological activity and on the North East Atlantic Ocean climate (see discussion in Le Cann and Serpette, 2009), Navidad events have received a lot of attention in the last decade. Thermal infrared satellite imagery has been widely used to study their occurrences. Garcia-Soto et al. (2002) have shown that the Navidad events' large interannual variability is related to the North Atlantic Oscillation index. Data from cruises, floats and moorings have also been used (among others: Frouin et al., 1990; Pingree and Le Cann, 1990; Torres and Barton, 2006; Le Cann and Serpette, 2009) but as noted by Le Cann and Serpette (2009), because of their large temporal variability from interannual to intraseasonal scales, Navidad events are difficult to observe with in situ measurements.

Caballero et al. (2008) analyse satellite altimetric data in the whole Bay of Biscay at seasonal and interannual time scales. Their data consist of 10-day maps built from a standard optimal interpolation scheme. As the IPC is described to be in geostrophic equilibrium, it is expected to have a signature in sea level. But, the depiction of a coastal current is not possible from present interpolated products and requires an along-track analysis. 'Standard' data processing (e.g. AVISO, 1996) is not appropriate to recover data points so close to the continent. The main two difficulties when dealing with coastal altimetry stem from the land signal contamination when the satellite flies from the continent to the ocean and from the corrections to atmospheric effects on the radar signal propagation. In particular, the wet tropospheric correction is derived from the onboard radiometer measurements that are strongly disturbed by the presence of land. A processing tool, X-TRACK, dedicated to altimetric data in the coastal domain, has been recently developed at CTOH (Centre de Topographie des Océans et de l'Hydrosphere, LEGOS, Toulouse). An experimental XTRACK dataset has been recently used by Le Hénaff et al. (2010) to study a 10-year time series of altimetric data along the TOPEX/ Poseidon track \#137 intercepting the northern Spanish coast close to $6.5^{\circ} \mathrm{W}$ over the period $1992-2002$. Their objectives were to identify and characterise the signature of Navidad events and of their variability at interannual time scales on this single track. The authors define indices from the across-track geostrophic velocity anomalies and from satellite SST images. They show that both indices agree well on the depiction of the four main Navidad events of the period 19921999; the agreement degrades for the following years for reasons that are not well understood. Our work is complementary to Le Hénaff et al.'s (2010) study in the sense that we extend the analysis to a larger set of tracks while we shorten the period of interest and focus on high-frequency variability ((O) few days) over the winter of 2004.

Our objectives are twofold. First, we aim to document the variability of the slope current along the northwestern Iberian coast from in situ data and from a numerical simulation in the winter of 2004; our goal is then to determine whether altimetric data are able to depict the occurrences of an eastward geostrophic anomaly signal associated with the Iberian Poleward Current. Secondly, we explore whether altimetry signals could provide additional information with respect to observations such as SST. Le Cann and Serpette (2009) report that 2004 is a year with no Navidad; their index is based on monthly $1^{\circ} \times 1^{\circ}$ interpolated SST data and allows for the depiction of strong Navidad events such as the winter of 2006. However, events with a weaker extent or amplitude or characterised by a shorter time scale variability may not be captured with such a criteria
(Garcia-Soto et al., 2002; Torres and Barton, 2006).The high-frequency variability of the IPC is not very well known and we believe that situations with pulses over a few days, coherent with the variability of atmospheric forcing, could occur without appearing in the generally used SST datasets. We therefore aim to investigate whether such situations could be revealed by altimetry.

The remainder of this paper is organised as follows: SST, buoys, altimetric data and the model used for this study are described in Section 2. In Section 3, we analyse the warm anomalies and episodes of surface eastward flow depicted in buoys and satellite SST observations and check the consistency of the simulated signals with these observations. This leads us to a general overview of the circulation in the winter of 2004. In Section 4 we analyse the signature of the circulation in the altimetric data and we discuss the complementary information provided by altimetry with respect to in situ and SST data. Conclusions are given in Section 5.

\section{Data and model description}

\subsection{Buoy data}

The deep sea network of Puertos del Estado (http://www.puertos.es/ es/index.html) is based on 6 Seawatch buoy stations along the Spanish coast (Alvarez-Fanjul et al., 2003). In this study, we use the four buoys located on the westernmost part of the coast (Fig. 1): Cabo de Peñas $\left(43^{\circ} 44^{\prime} \mathrm{N}, 6^{\circ} 10^{\prime} \mathrm{W}\right.$, mooring depth: $\left.450 \mathrm{~m}\right)$, Estaca de Bares $\left(44^{\circ} 3.6^{\prime} \mathrm{N}\right.$, $7^{\circ} 37.2^{\prime} \mathrm{W}$, mooring depth: $\left.382 \mathrm{~m}\right)$, Villano Sisargas $\left(43^{\circ} 29.4^{\prime} \mathrm{N}, 9^{\circ} 12.6^{\prime} \mathrm{W}\right.$, mooring depth: $386 \mathrm{~m})$ and Cabo Silleiro $\left(42^{\circ} 7.2^{\prime} \mathrm{N}, 9^{\circ} 24.0^{\prime} \mathrm{W}\right.$, mooring depth: $323 \mathrm{~m}$ ). Hereafter, the buoys will be referred to as Peñas, Bares, Villano and Silleiro, respectively. We use the surface temperature and current (direction and velocity), measured at $3 \mathrm{~m}$ below the surface and the surface wind (direction and velocity) measured at $3 \mathrm{~m}$ above the ocean. A Loess filter with a window of $48 \mathrm{~h}$ is applied on the hourly current data to remove tidal and inertial currents. The data are then averaged over $24 \mathrm{~h}$ to be compared with the daily model outputs. No subsurface measurements were available in the area during the period of study.

\subsection{Sea surface temperature data}

We have retrieved daily SST fields from AVHRR Pathfinder and MODIS from the JPL-PODAAC web site (http://podaac.jpl.nasa.gov). Unfortunately, because of frequent cloudy conditions, the number of available images over the autumn-winter period is very limited (only ten usable images in the winter of 2003-2004). We also analyse daily gridded SST fields from the Centre Météorologique Spatial of MétéoFrance, hereafter referred to as the 'CMS dataset'. An optimal interpolation method is used to combine SST data from buoys and from satellite infra-red observations, with the previous analysis used as first-guess field. Satellite data are obtained from the EUMETSAT Ocean \& Sea Ice Satellite Application Facility GOES-East and MSG products as well as from the US-Navy NOAA-16 and 17 global products (AVELMOR, Final report, 2002). The CMS fields are provided on a $0.1 \times 0.1^{\circ}$ grid, over the Atlantic Ocean. They offer an interesting alternative as the missing data are filled using optimal interpolation and additional measurements are taken into account. However one must keep in mind that the number of cloud free images remains very low, so the SST time variability is under-estimated and the spatial distribution can be locally too smoothed.

\subsection{Altimetric data}

Altimetric data from TOPEX/Poseidon (T/P) and Jason-1 (J1) have been extracted over the period Oct. 2002-Oct. 2005. This choice has been made for two reasons: firstly, this period corresponds to the tandem mission of $\mathrm{T} / \mathrm{P}$ and J1. Both satellites are flying over the same region on the same day, $\mathrm{T} / \mathrm{P}$ ground tracks falling mid-way between those of J1: such a 


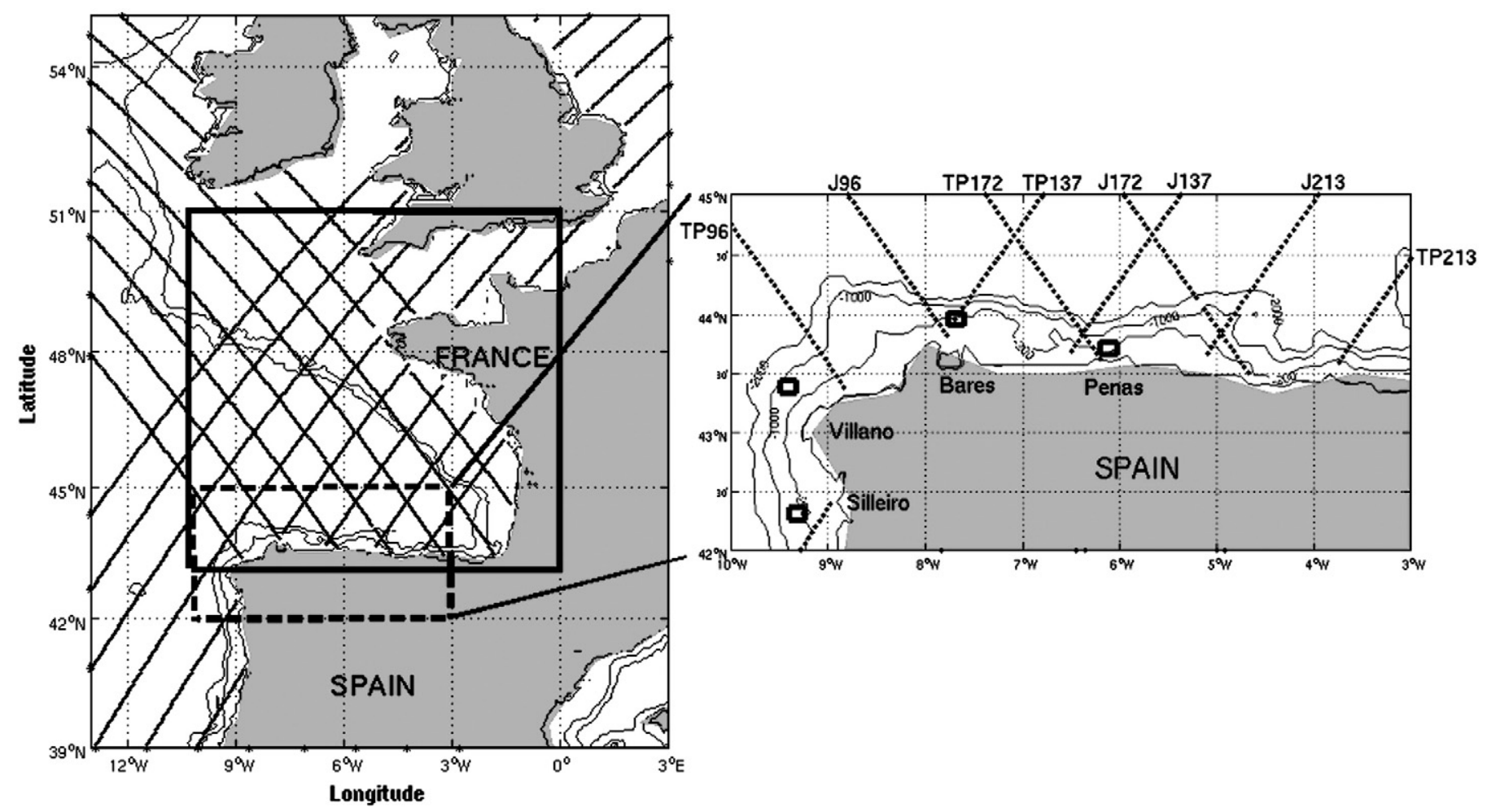

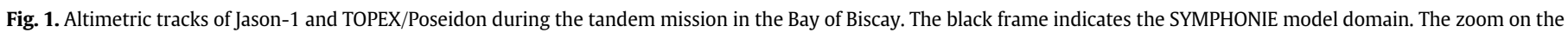

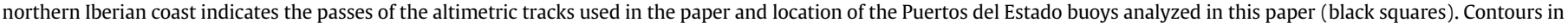
black indicate $200 \mathrm{~m}, 1000 \mathrm{~m}$ and $2000 \mathrm{~m}$ isobaths.

configuration doubles the resolution of the altimetric data. Secondly, a simulation has been made over the year 2004 and its main characteristics have been assessed with respect to available observations and other simulations. Fig. 1 shows the paths of the two satellites; their repetitivity cycle is about 9.9 days.

The data have been reprocessed from the GDR (Geophysical Data Record distributed by AVISO) data stream at a rate of $1 \mathrm{~Hz}(\sim 6 \mathrm{~km}$ alongtrack spacing) using the X-TRACK processing tool (more information on http://ctoh.legos.obs-mip.fr and in Roblou et al., 2010). Usual geophysical corrections are applied (see Table 1). The instrumental background noise is filtered using a Loess filter with a $35 \mathrm{~km}$ cut-off length, which is a compromise between noise reduction and a limited smoothing of the sea level slope. X-TRACK proceeds with specific editing criteria both on the altimeter measurements and on the correction terms. The editing criteria first imposed on the corrections are more restrictive than the standard ones (AVISO, 1996) but in a second step, the missing corrective terms are interpolated from the valid ones available in the neighbourhood (Vignudelli et al., 2005). This approach allows the retrieval of a significant number of altimetric measurements that would be flagged otherwise. Therefore our dataset includes more data points close to the coast than the standard AVISO product. Continuous developments are in progress on the processing of coastal altimetric data, and on the use of higher resolution along-track data (e.g. Cipollini et al., 2010). Our objective here is not to explore up-to-date techniques in terms of data processing. Instead, we aim to characterise the potential benefit of a routine coastal altimetric XTRACK product, actually the dataset supplied through the ECOOP project (European COastal-shelf sea OPerational observing and forecasting system, www.ecoop.eu) for the study of a seasonal slope current. The benefit of such a dataset has been illustrated in a few recent papers: see for instance the study of a narrow coastal current (the Liguro-Provençal current) in the Mediterranean Sea by Birol et al. (2010).

In this paper, we analyse along-track Sea Level Anomalies (SLA) computed with respect to the mean over the year 2004. As the IPC in 2004 does not penetrate far towards the east, we focus on tracks west of $4^{\circ} \mathrm{W}$. Since the tracks are almost perpendicular to the northern Iberian coast, a sea level elevation at the coast means an eastward geostrophic current whose direction is nearly zonal. We estimate the anomalies of the geostrophic velocity perpendicular to the track using a classical finite difference scheme with a 3-point central difference operator. In addition to the SLA filtering (as mentioned earlier), we apply a Loess filter with a $30 \mathrm{~km}$ cut-off length to reduce the noise in the slope computation.

\subsection{Model set up}

Our simulation is based on the 3D regional coastal model SYMPHONIE, developed at the Pôle Océan et Couplages (POC, Toulouse) (Marsaleix et al., 2008, 2009). It is a free surface, primitive equation model with vertical generalised sigma coordinates. We use it in its hydrostatic version. The resolution is about $3 \times 3 \mathrm{~km}$ on a MERCATOR projection, with 43 vertical levels. The integration domain extends from $43.2^{\circ} \mathrm{N}$ to $50^{\circ} \mathrm{N}$ and from $10.5^{\circ} \mathrm{W}$ to $0.5^{\circ} \mathrm{W}$ (Fig. 1). The model is forced at its boundaries by daily fields of temperature, salinity and horizontal velocity from MERCATOR-Océan products and by tidal harmonic components from the FES2004 solution (Lyard et al., 2006). At the surface, the air-sea fluxes are computed from the CORE bulk formulae (Large and Yeager, 2004) and 3 hourly atmospheric variables from ALADIN/Météo-France: air-temperature at $2 \mathrm{~m}$, wind velocity at $10 \mathrm{~m}$, specific humidity at $2 \mathrm{~m}$, radiative fluxes, and precipitations. The ALADIN field horizontal resolution is $0.1^{\circ}$. Vertical physics is represented using the 1.5 order closure scheme of Gaspar et al. (1990) that models the turbulent kinetic energy evolution with mixing scales controlled by stratification. The model is run from Dec. 15, 2003 to Dec. 31, 2004. Our analyses are based on daily averaged outputs. A simulation over 2004 in a nearly identical configuration has been studied within a project of model intercomparisons in the Bay of Biscay (Reffray et al., 2008). The same model configuration, but with slightly different open-boundary 
Table 1

List of geophysical corrections applied to the T/P and J1 datasets.

\begin{tabular}{|c|c|c|}
\hline Correction & $\mathrm{T} / \mathrm{P}$ & $\mathrm{J} 1$ \\
\hline Ionosphere & $\begin{array}{l}\text { Dual-frequency ionospheric correction }+ \\
\text { GCP correction (GDR correction product) }\end{array}$ & Altimeter ionospheric correction \\
\hline Dry troposphere & Surface pressure from the ECMWF model & $\begin{array}{l}\text { Surface pressure from the ECMWF } \\
\text { model and model for S1 and S2 tides }\end{array}$ \\
\hline Wet troposphere & $\begin{array}{l}\text { Radiometer wet tropospheric correction } \\
\text { + GCP correction of radiometer drift effects } \\
\text { + GCP correction of yaw effects }\end{array}$ & $\begin{array}{l}\text { Radiometer wet tropospheric correction } \\
\text { on Ku-band }\end{array}$ \\
\hline High frequency atmospheric forcing & $\begin{array}{l}\text { For periods shorter than } 20 \text { days: corrections } \\
\text { from the T-UGO global simulations } \\
\text { Carrère and Lyard ( } 2003 \text { ) } \\
\text { For periods greater than } 20 \text { days: inverted } \\
\text { barometer corrections }\end{array}$ & $\begin{array}{l}\text { For periods shorter than } 20 \text { days: } \\
\text { corrections from } \\
\text { the T-UGO global simulations } \\
\text { Carrère and Lyard (2003) } \\
\text { For periods greater than } 20 \text { days: } \\
\text { inverted barometer corrections }\end{array}$ \\
\hline Ocean tides & From FES2004 numerical model (Lyard et al., 2006) & From FES2004 numerical model (Lyard et al., 2006) \\
\hline Solid tides & Solid earth tide height formula & Solid earth tide height formula \\
\hline Loading effect & Load tide height for geocentric ocean tide FES1999 & Load tide height for geocentric ocean tide FES1999 \\
\hline Pole tides & Geocentric polar tide height (Wahr, 1985) & Geocentric polar tide height (Wahr, 1985) \\
\hline Sea state bias & $\begin{array}{l}\text { Electromagnetic bias Ku-band correction (BM4) } \\
\text { + GCP correction (Chambers et al., 2003) } \\
\text { + GCP correction of non parametric electromagnetic bias (Gaspar et al., 1994) }\end{array}$ & Sea state bias correction on Ku-band \\
\hline
\end{tabular}

Note that the corrections for the ionosphere, wet troposphere and sea state bias effects are different for T/P and J1.

conditions, has also been used by Le Hénaff (2008). The tidal solution has been assessed by Pairaud et al. (2008). The reader is therefore referred to these previous studies for the model validation.

\section{Overview of the circulation along the northern Iberian coast during the winter of 2004}

\subsection{From SST satellite observations and buoys data}

On the available satellite SST images (see for instance Fig. 2a for Jan. 20, 2004), we observe 'tongues' of warm water $\left(\sim 13.5-14{ }^{\circ} \mathrm{C}\right)$, that originate from the western Iberian coast and progress eastwards along the northern Iberian coast with decreasing SST values. The warm tongues usually do not appear as continuous and homogeneous veins along the coast but rather display large spatial variations such as 'patches' along the coast. This can be the signature of interactions with the offshore circulation or with local processes linked to local forcing or small scale bathymetric features. We also observe large variations from one day to another. For a more detailed investigation into the dates of the warm tongue occurrences, we analyse CMS maps (see for example maps for Jan. 31 and Feb. 1, 2004 in Fig. 2b). They show 'pulses' of warm water intrusion that do not extend far along the Spanish coast (often limited to $7-8^{\circ} \mathrm{W}$ ) with a short duration (a few days). Such pulses are observed around Dec. 15, Jan. 10, Jan. 17-25, and Feb. 1-5, with a west-east weakening of the SST signal.

This weakening along the coast is well visible in the time series of daily SST at the buoys presented in Fig. 3 (e.g.: $\sim 0.5{ }^{\circ} \mathrm{C}$ from Villano to Peñas on Jan. 15). We note that the warming associated with the pulses is sporadic: instead of a temperature rise, it just tends to hide the seasonal cooling and is thus rather difficult to interpret. However, based on the previous analysis of AVHRR and CMS maps, we can identify some 'warm' events (grey fields in Fig. 3): mid December, end of December, early January, midJanuary, early February and end of March.

From current measurements at buoys (Fig. 4), these periods of positive SST anomaly can be related to eastward current along the northern Iberian coast with amplitudes of 0.1 to $0.25 \mathrm{~m} / \mathrm{s}$. In agreement with SST maps, the signals appear more as pulses over a few days than as a continuous current over a few weeks. Moreover, the current shows a high spatial variability: at neighbouring buoys, its strength and its direction may vary significantly. For example, in mid December 2003 and January 2004, larger velocities are measured at Peñas than at Bares. Local forcing mechanisms, such as bathymetry or local atmospheric features, may impact the current. But this may be as well an 'observability issue' due to the different locations of the buoys with respect to the slope geometry and bathymetry. The interpretation of the buoy current measurements is therefore limited by the large variability at small spatial scales (in both along-shore and cross-shore directions) that is suggested by SST images and by the differences between consecutive buoys.

The winds associated with this circulation (shown in Fig. 4) are primarily meridional at Silleiro and Villano, and zonal at Bares and Peñas. Large time variability is found with wind reversals over 2-3 day episodes. As expected, in general, northeastward winds at the western Iberian coast are associated with eastward flow along the northern coast. However, the spatial variations of the current's intensity along the northern coast suggest the influence of local wind forcing (discussed in Section 3.3).

\subsection{From the model}

3.2.1. Assessment of the model's ability to simulate the observed surface variability

Fig. 5 shows the model surface temperature and zonal current variations as a function of time and latitude at the closest point to the Bares buoy $\left(7.62^{\circ} \mathrm{W}\right)$ over the period Jan-Mar 2004. Pulses of warm eastward flow can be identified with maximum velocities of $0.4 \mathrm{~m} / \mathrm{s}$ associated with relatively high values of SST (13.1 to $13.3^{\circ} \mathrm{C}$ ) south of $44^{\circ} \mathrm{N}$, over the shelf and upper slope. A succession of SST pulses is observed from Jan. 11 to Jan. 25, from Feb. 1 to Feb. 17 and from Mar. 18 to Mar. 24 2004. They are also observed near Peñas but with weaker SST signals ( 12.8 to $12.9^{\circ} \mathrm{C}$ ) with no obvious time lag between the pulses at the two locations (not shown).

In comparison with the CMS data, values are lower during the main pulses $\left(-0.3 /-0.4{ }^{\circ} \mathrm{C}\right)$. In mid-March 2004 (Fig. 5), an SST maximum in the model develops at the coast whereas the CMS dataset indicates weak warm anomalies with respect to the January and February ones. In late February-early March, we notice a shift of the main vein of the eastward current with respect to the coast: a very narrow tongue of colder water $\left(\sim 12.4^{\circ} \mathrm{C}\right)$ develops along the coast while warmer water masses $\left(\sim 12.6-12.7^{\circ} \mathrm{C}\right)$ are still observed at $44^{\circ} \mathrm{N}$. It seems to be related to the change of winds' direction from eastward to westward (see Fig. 4 for wind measurement from buoys). In the CMS data, there is no clear detection of this thin tongue of cold water and the SST data at the buoys do not allow us to evaluate further the realism of this cold tongue in the model. 


\section{a. Infrared SST images}
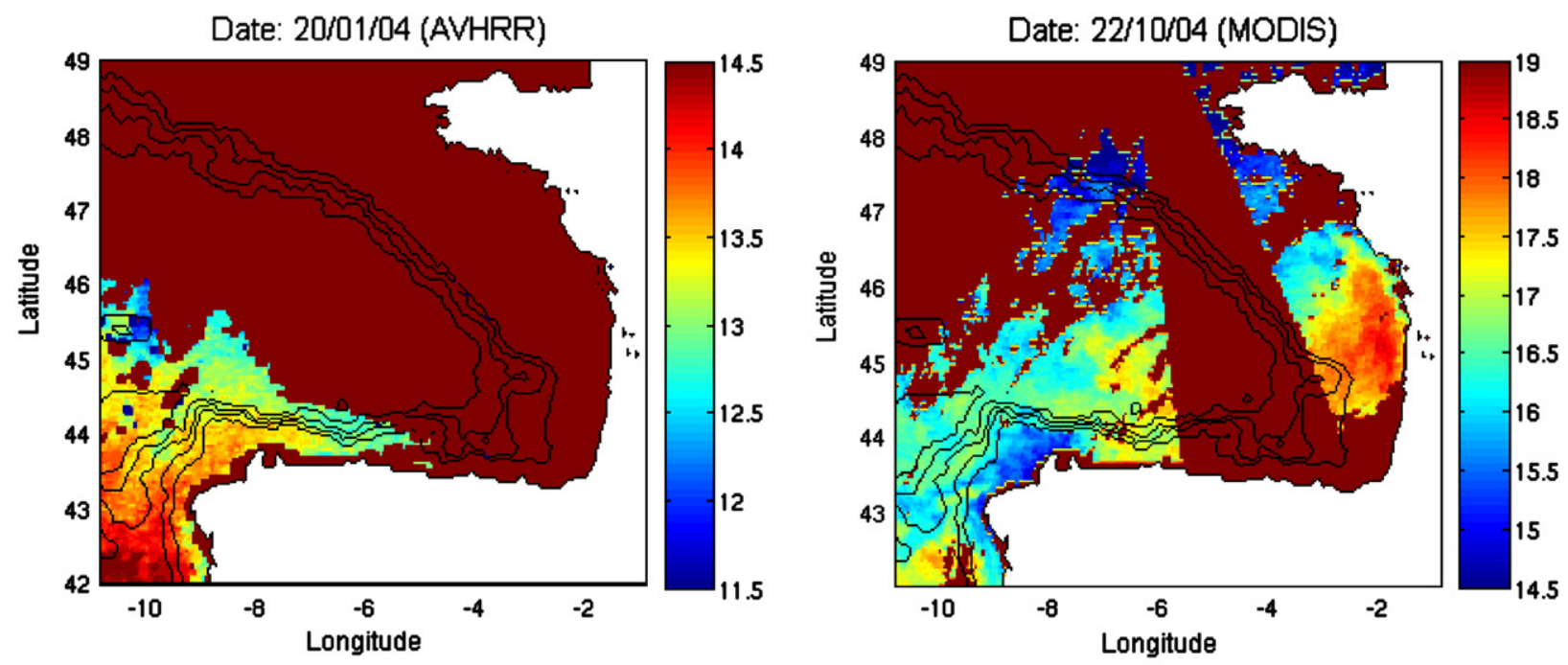

\section{b. Interpolated SST data (CMS dataset)}
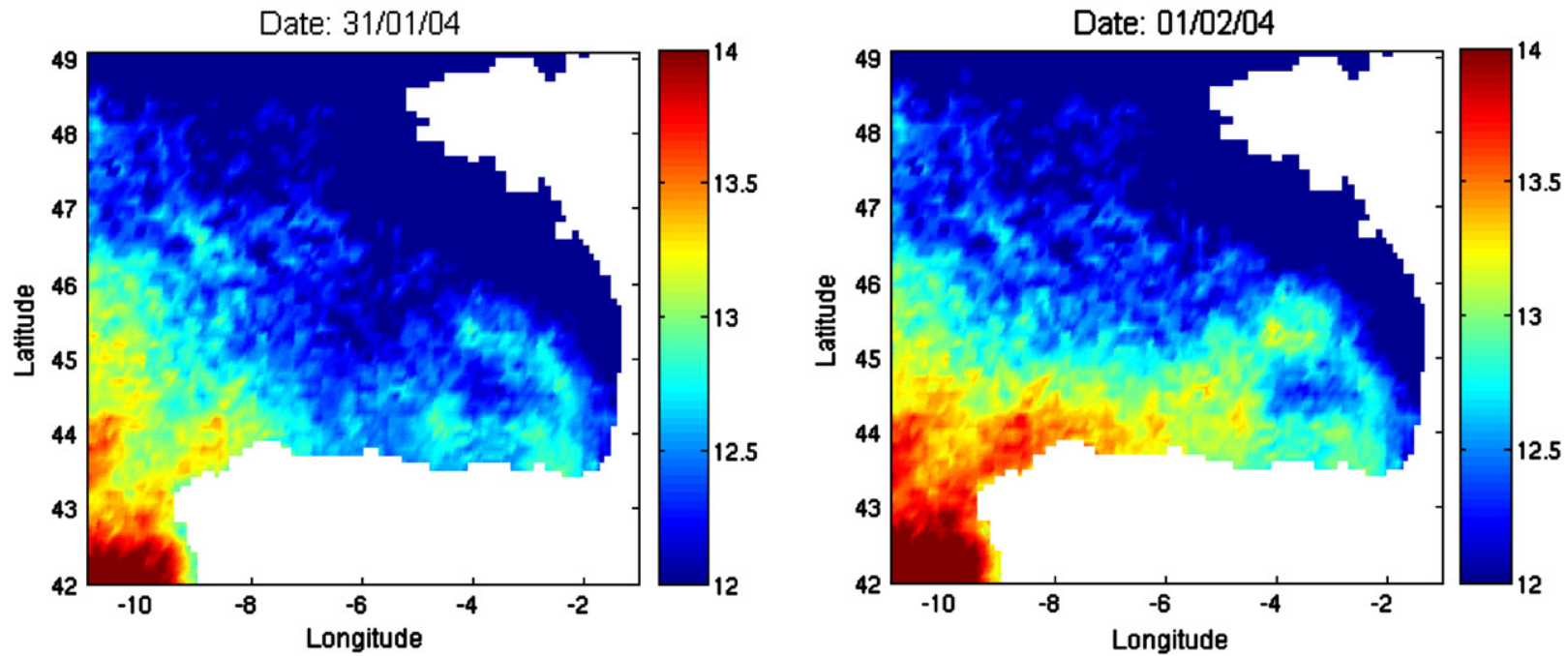

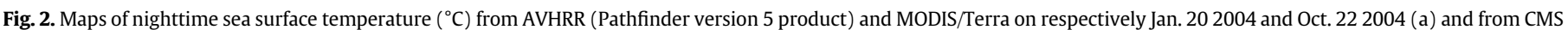
dataset (Centre Météorologique Spatial of Météo-France) for Jan. 312004 and Feb. 12004 (b).

The model surface zonal current is consistent with the observations at the buoys (see Fig. 6). The agreement is very good for the January event (Jan. 6-17), in particular in the representation of the three pulses. The simulated current (in black) at the closest grid point to the buoy well reproduces the high frequency variations of the observed current. Indeed, the correlation between the zonal observed and simulated velocity anomalies over the Jan-Mar 2004 period varies from 0.85 at Villano to 0.67 at Peñas (significant at the $99 \%$ level). The root mean square of the differences is about $8 \mathrm{~cm} / \mathrm{s}$ (Fig. 6). The simulation indicates stronger eastward zonal current at Peñas than at Bares over the whole Jan.-Mar. period. This is also observed in the buoys data but for the January event alone. Indeed, during the midFebruary-mid March period, three pulses of eastward current are simulated, weaker than for the January event: on Feb. 27-29 (mainly at Peñas), around Mar. 5 and over the period Mar. 10-20 with a maximum around Mar. 12. The pulses in March correspond to those previously reported in the data analysis, except close to Peñas, where the model tends to overestimate the zonal current with respect to the buoy data $(+0.15 \mathrm{~m} / \mathrm{s}$ on the zonal current anomalies). The model overestimation of the current near Peñas can be related to the complexity of the topography in this area. Current intensifications are also observed near $4^{\circ} \mathrm{W}$ along the coast where the bathymetry is also disrupted by canyons. Besides, the model bathymetry suffers from inaccuracies that result from errors in the initial bathymetry and/or in the smoothing and sigma-levels representation which would tend to modify the slope or shift it closer to the coast. We have checked the water column depth in the model close to the buoys location. Unexpectedly, it is close to the real depth at Peñas $(412.5 \mathrm{~m}$ in the model vs. $450 \mathrm{~m}$ in reality) whereas there is a significant discrepancy at Bares (724 m in the model vs. $382 \mathrm{~m}$ in reality).

We have also compared the wind speed and direction as measured at the buoys with the ALADIN fields over the period January-March 2004 and found consistent values and variability.

\subsubsection{Subsurface temperature and velocity fields}

Consistent temperature and zonal current signals with those described in the surface are observed at $127 \mathrm{~m}$ depth (Fig. 7). The subsurface flow appears as a specific along-shore pattern while in 
$\mathrm{T}^{\circ} \mathrm{C}$

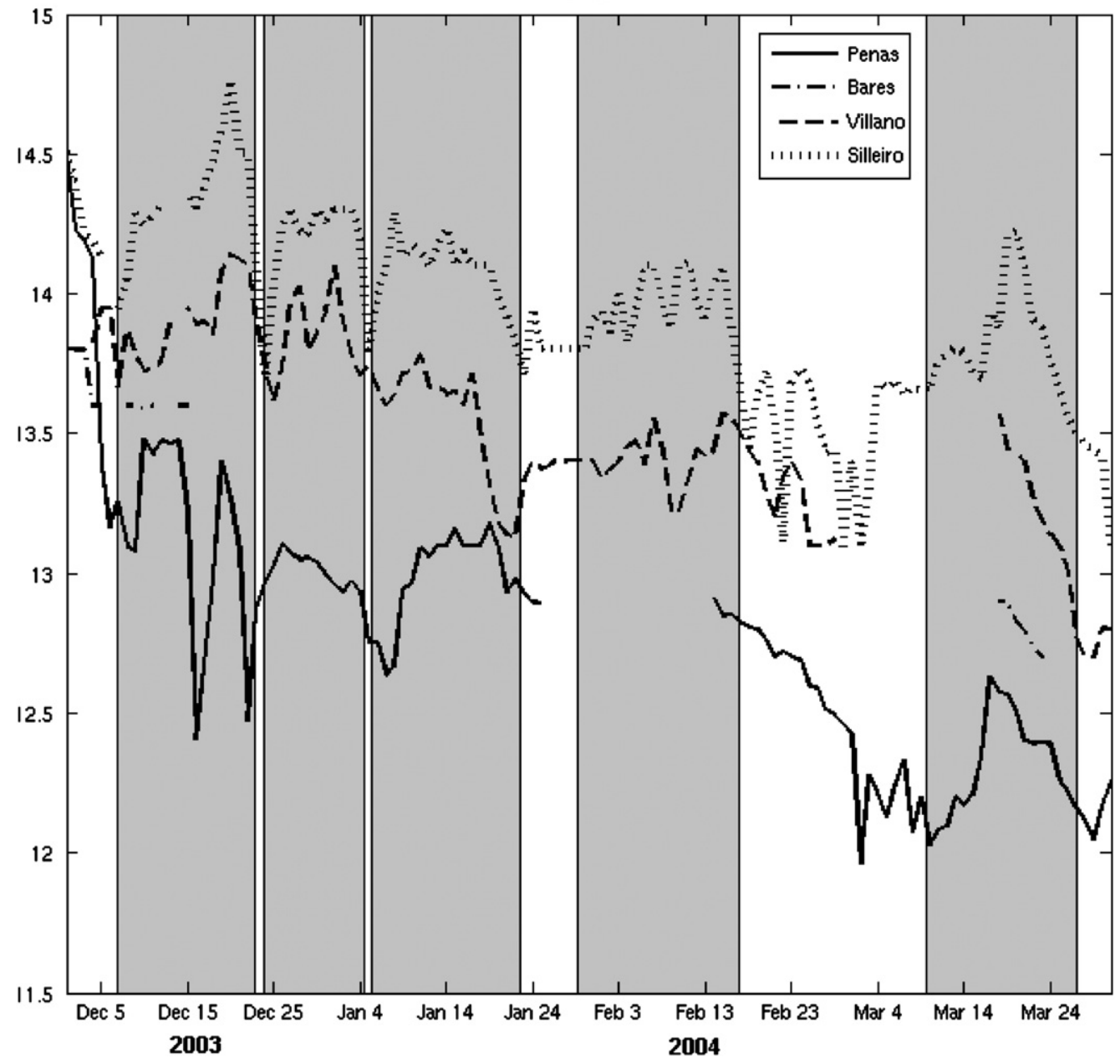

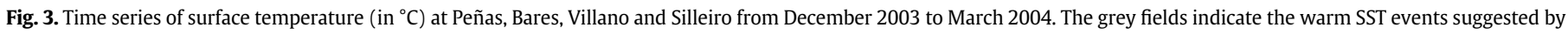
the analysis of SST satellite images. Note that temperature data at Bares is missing for most of this period.

surface, the pulses over the shelf seems correlated with the circulation offshore, likely because of the large scale Ekman flow. Fig. 8 shows vertical structures of the temperature and zonal velocity during the two events of January and February from the model on two transects over the northern slope (at the longitude of Bares: $7.62^{\circ} \mathrm{W}$ and Peñas: $\left.6.17^{\circ} \mathrm{W}\right)$, and at the southern open boundary of the model $\left(\sim 43^{\circ} \mathrm{N}\right)$. The main current vein is located above the upper slope between 100 and $200 \mathrm{~m}$ at Bares and Peñas locations. At $7.62^{\circ} \mathrm{W}$, a vein of eastward flow can be identified from the coast to $43.9^{\circ} \mathrm{N}$ with a maximum velocity at surface $(0.45 \mathrm{~m} / \mathrm{s}$ and $0.25 \mathrm{~m} / \mathrm{s}$ on Jan. 13 and Feb. 1 respectively) and extending down to $200 \mathrm{~m}$. At $6.17^{\circ} \mathrm{W}$, we note an eastward flow close to the coast, with a maximum of $0.35 \mathrm{~m} / \mathrm{s}(0.15 \mathrm{~m} / \mathrm{s})$ on Jan. 13 (Feb. 1 ) at the surface and extending to $300 \mathrm{~m}$ further offshore $\left(43.7^{\circ} \mathrm{N}\right.$ to $\left.43.8^{\circ} \mathrm{N}\right)$. The pattern of the near-surface flow when approaching Cabo Peñas (at $6.17^{\circ} \mathrm{W}$ ) seems to be affected by the topography (as previously suggested), which is particularly steep and rugged in this region.

Also, clearly seen in Fig. 8 is the relatively warm water tongue extending south of $44^{\circ} \mathrm{N}$, over the shelf and upper slope, down to 200$250 \mathrm{~m}$. On Jan. 13, the SST gradient between the shelf and the area more offshore is $0.6^{\circ} \mathrm{C}$ at $7.62^{\circ} \mathrm{W}$. The temperature signal decreases towards the east. Over the whole study period, warm SST and subsurface signals are associated with the velocity pulses, but a time lag of a few days between the pulse of warm surface inflow and eastward surface current are observed (e.g. Jan. 6-15). Warm anomalies are also found to persist for several days after the eastward current has vanished. This may correspond to situations where atmospheric conditions are not favourable to mixing and/or cooling. During the Navidad event of December 2006, Le Cann and Serpette (2009) also observe a warm tongue at $5^{\circ} 30^{\prime} \mathrm{W}$ while the current is westward.

Although Navidad events are usually described in the literature as warm and saline anomalies, the salinity signal from the model during the Jan.-Mar. 2004 period shows a more complex time evolution than temperature, with no clear correspondence with the eastward pulses (not shown). Indeed, Le Cann and Serpette (2009) note that the years of warm inflows do not always coincide with years of anomalous salinity. They suggest that different physical forcings are responsible for temperature and salinity anomalies.

At the southern open-boundary $\left(\sim 43^{\circ} \mathrm{N}\right)$, relatively high values of temperature (up to $13.44^{\circ} \mathrm{C}$ at $9.3^{\circ} \mathrm{W}$ from the surface to $80 \mathrm{~m}$ on Feb. 1) are observed over the upper slope between the coast and $9.5^{\circ} \mathrm{W}$ (Figs. 8d

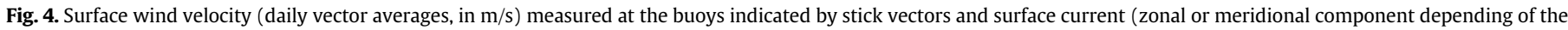

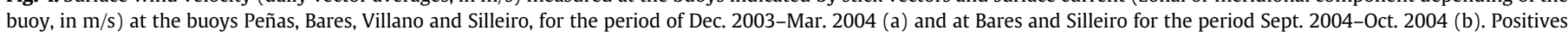
values of zonal (meridional) current indicate eastward (northward) current. 

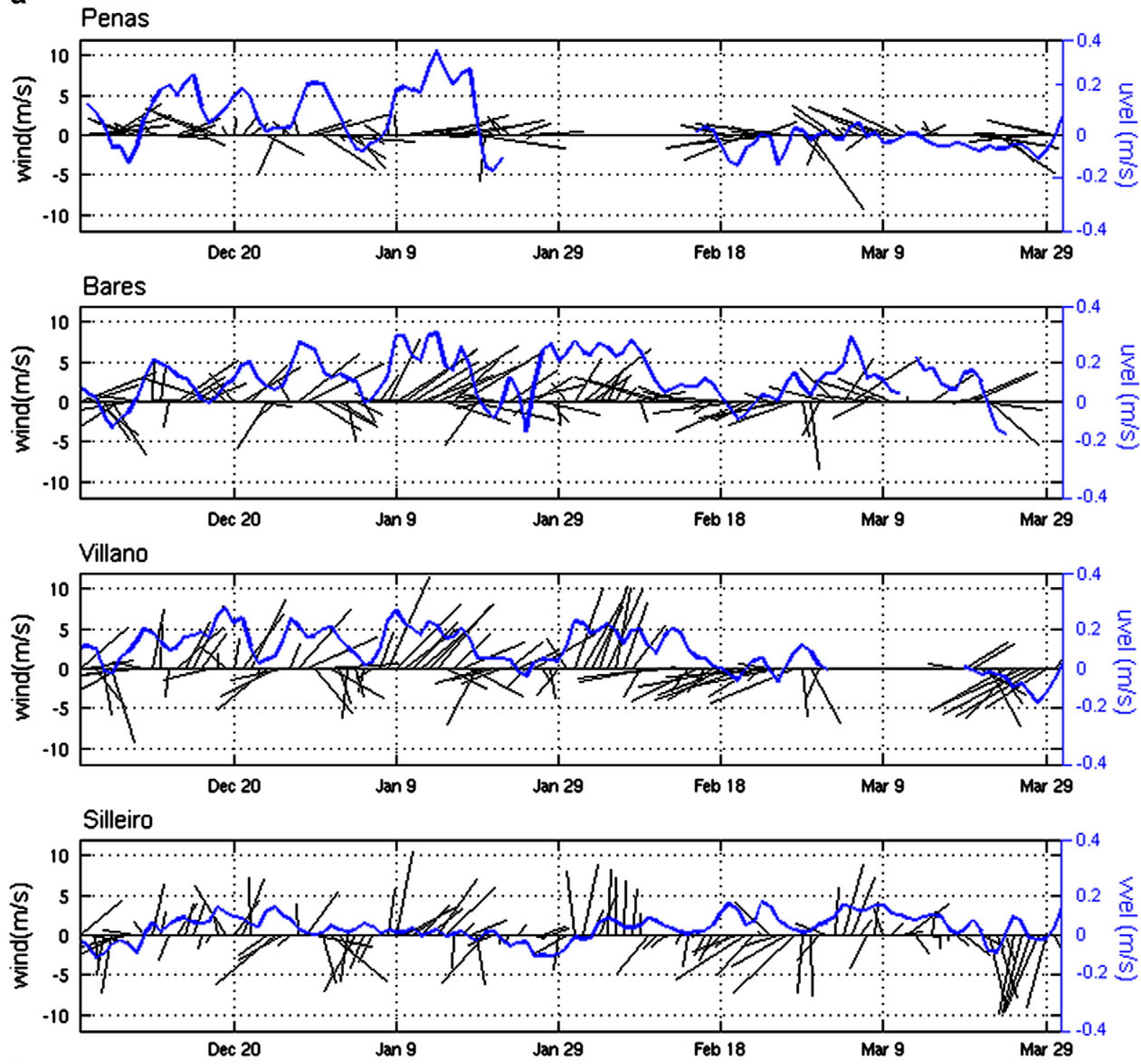

b

Bares

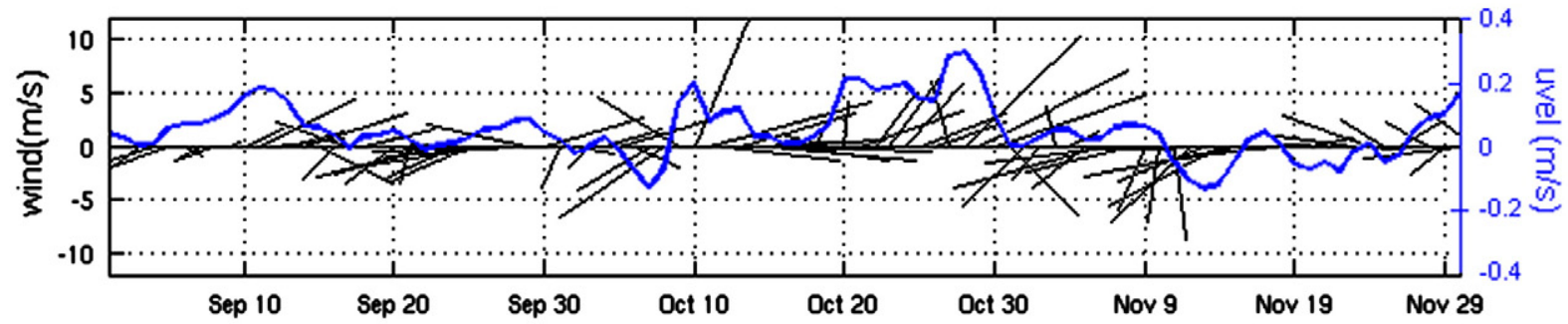

Silleiro

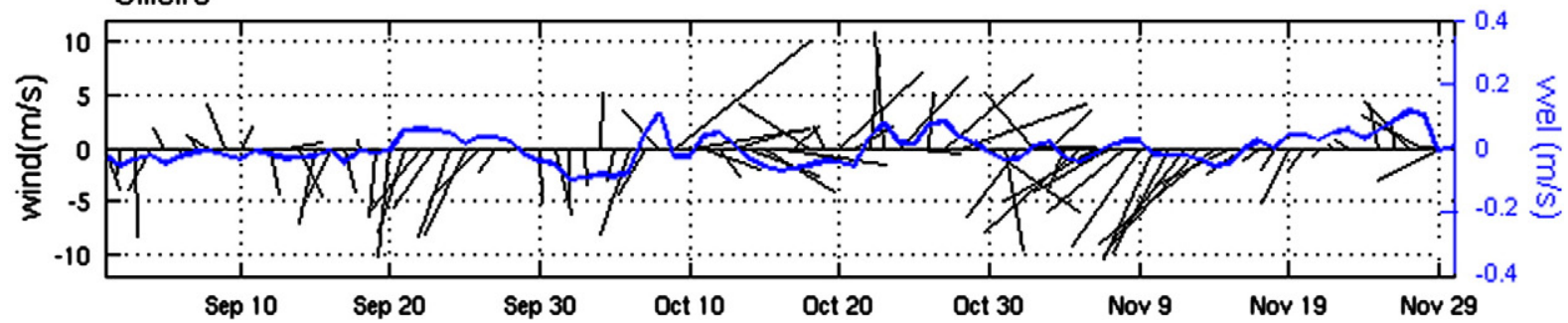


Surface temperature $\left({ }^{\circ} \mathrm{C}\right)$

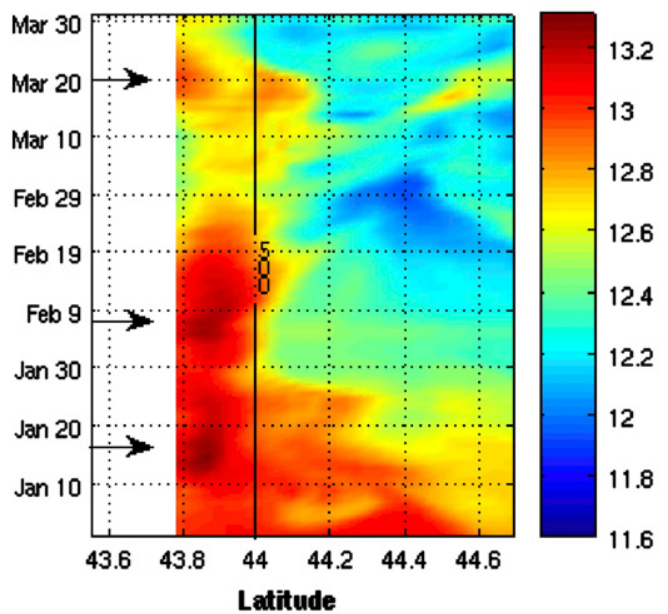

Surface zonal current (m/s)

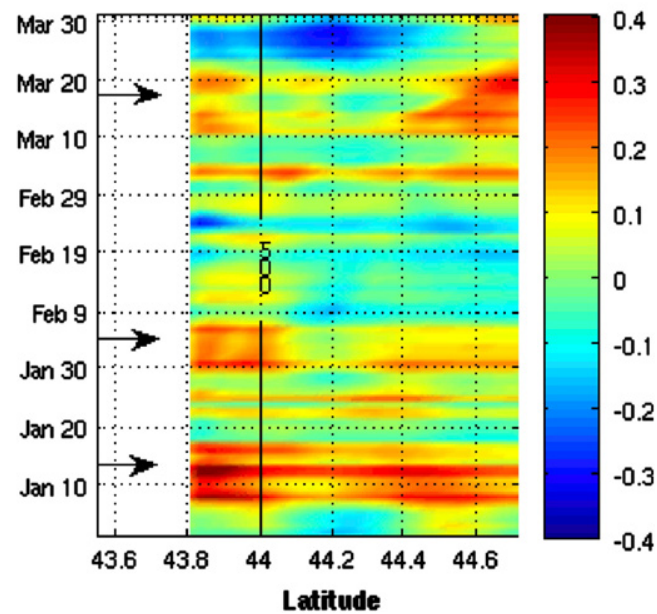

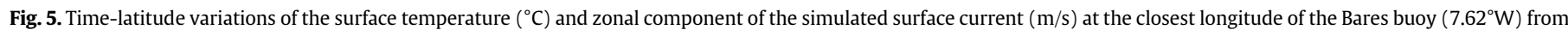
Jan. to Mar. 2004. Positive values correspond to eastward current. The isobath $500 \mathrm{~m}$ is indicated by the thin black line.

\section{Zonal current anomalies $(\mathrm{m} / \mathrm{s})$ at Peñas}

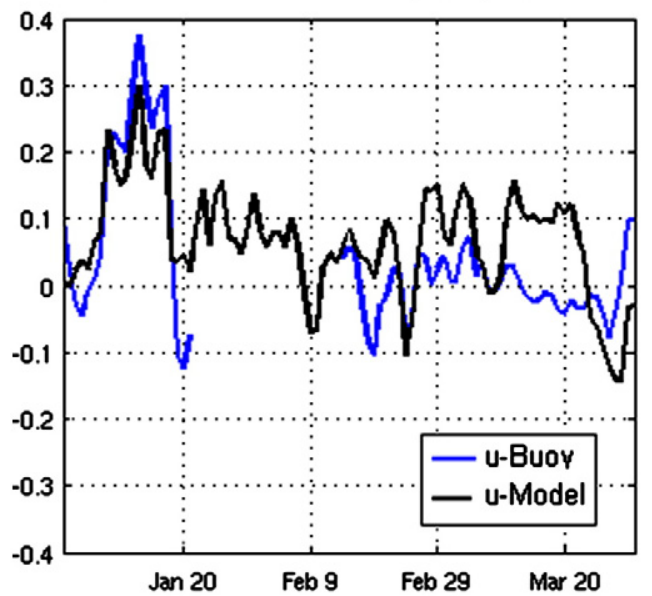

Zonal current anomalies $(\mathrm{m} / \mathrm{s})$ at Villano

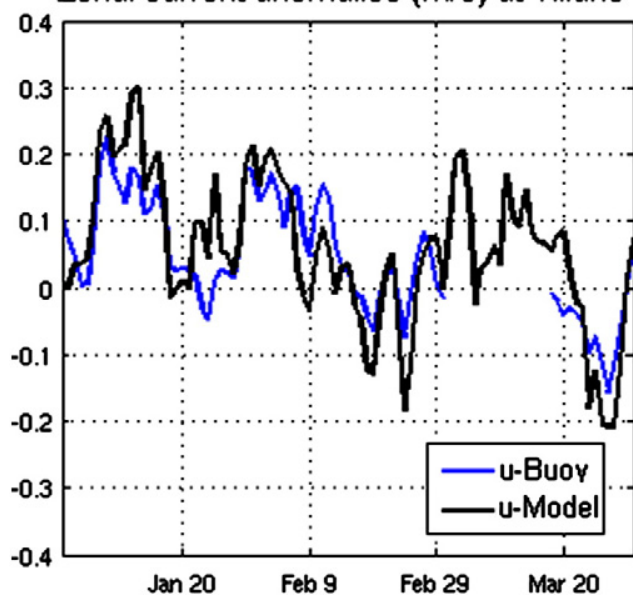

Zonal current anomalies (m/s) at Bares

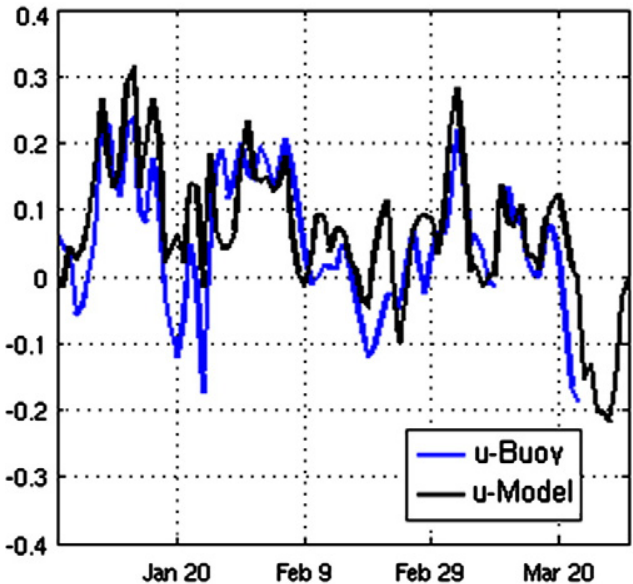

Meridional current anomalies $(\mathrm{m} / \mathrm{s})$ at Silleiro

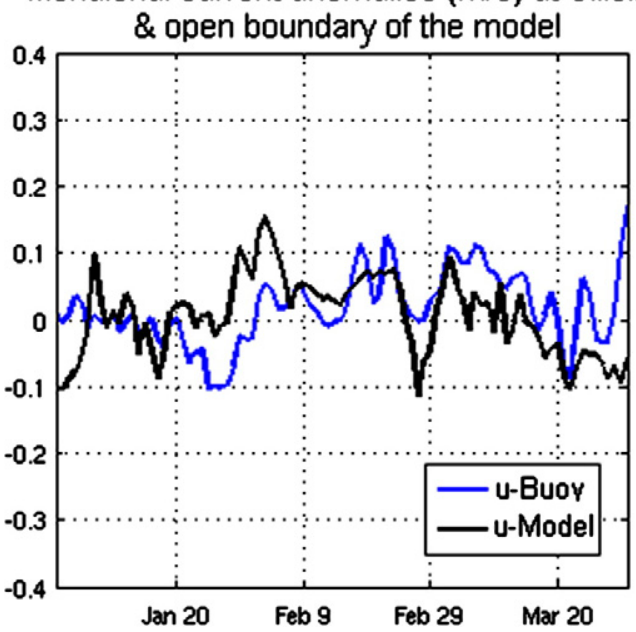

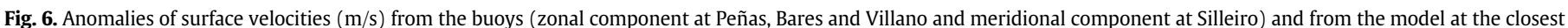

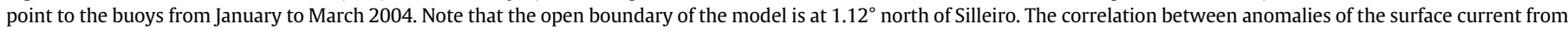

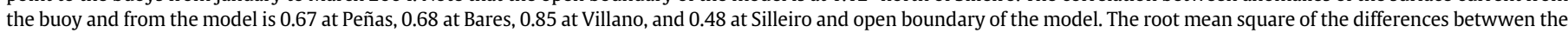
anomalies of surface zonal velocities from the model and from the buoys is $8.77 \mathrm{~cm} / \mathrm{s}$ at Peñas, $8.17 \mathrm{~cm} / \mathrm{s}$ at Bares, and $6.42 \mathrm{~cm} / \mathrm{s}$ at Villano. 
Temperature $\left({ }^{\circ} \mathrm{C}\right)$ at $127 \mathrm{~m}$

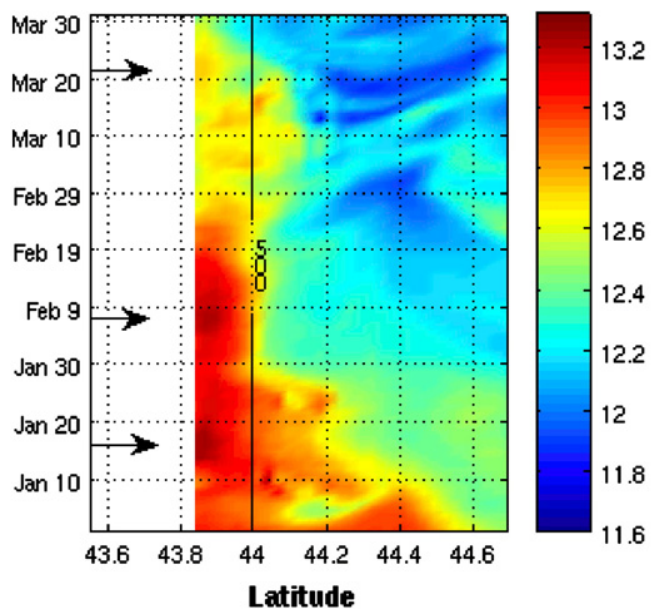

Zonal current (m/s) at $127 \mathrm{~m}$

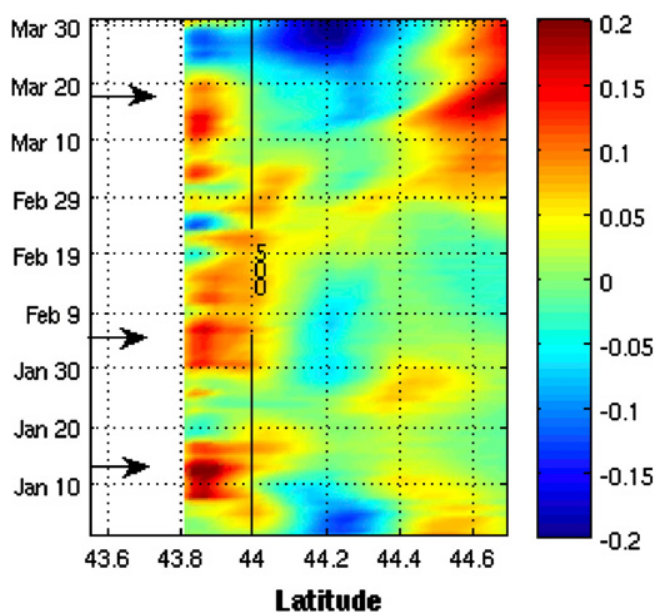

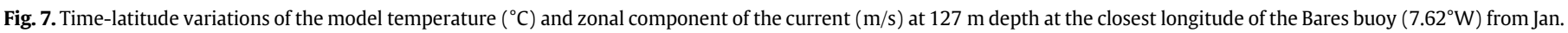
to Mar. 2004. Positive values correspond to eastward current. The isobath $500 \mathrm{~m}$ is indicated by the thin black line.

and 9). The current shows consistent conditions with a poleward flow over the upper slope and down to 200-300 m. However the velocities are weaker than those observed along the northern Iberian coast, with typical speeds reaching respectively $0.15 \mathrm{~m} / \mathrm{s}(0.2 \mathrm{~m} / \mathrm{s})$ in surface and $0.06 \mathrm{~m} / \mathrm{s}$ $(0.1 \mathrm{~m} / \mathrm{s})$ in subsurface during the January (February) event (Fig. 9). Having weaker currents at the southern boundary than along the northern Iberian coast during the main events suggests the influence of local forcing over the northern Iberian area.

\subsection{Influence of local forcing}

As noted previously from the current measurements at the buoys, the spatial variations of the current intensity along the western and northern Iberian coasts suggest the influence of local processes, such as local wind. For instance, the establishment of the eastward current at Bares on Jan. 26 (Fig. 4) preceeds by 3-4 days the one at Villano and by 5-6 days the northward pulse at Silleiro (Feb. 1). As the wind measured at the buoys (Fig. 4) is eastward at Bares while highly variable at Villano and Silleiro until Feb. 1, we suggest that the eastward flow at Bares is the signature of two distinct mechanisms: Ekman current until Feb. 1 and, from Feb. 1 Ekman current combined with the intrusion of the IPC from the south.

In the same way, during the January event, the current observed at Silleiro is very weak $(<0.02 \mathrm{~m} / \mathrm{s})$ (Fig. 4). We suggest that the eastward flow at Bares is partly fed by slope waters from the south (western Iberian coast) and enhanced by local north-eastward wind. Interestingly, from Feb. 8 and until Feb. 25, the meridional surface current west of Iberia both in the model (at $43^{\circ} \mathrm{N}$ ) and in the observations at Silleiro remains northward (Figs. 4 and 9), with surface amplitude of $0.10-0.15 \mathrm{~m} / \mathrm{s}$, whereas the winds reverse towards the west and south-west. At the same time, the surface flow at Bares weakens significantly, or even becomes westward (e.g. around Feb. 19, Fig. 4). Such a situation (northward inflow at the western Iberia coast with a priori upwelling favourable wind conditions) is similar to the one characterised by Otero et al. (2008) over the period Nov.-Dec. 2002. They show that the IPC is present over the whole period and that its surface signature is very sensitive to wind events at daily time scales. Indeed, their results reveal that while the poleward flow is subsurface intensified over the shelf and slope during downwelling - northward - winds, it becomes surface intensified when the northward winds relax or even during upwelling - southward - wind events. However, even if the surface velocities during upwelling events can reach higher values than those observed during downwelling events, the section of the northward flow is reduced and the northward transport is decreased. The weakness of the eastward flow observed on the northern Spanish coast underlines the role of the local winds that, when blowing westwards, tend to prevent the IPC from extending along the northern Spanish coast in surface.

\subsection{Conclusion on the situation in the winter of 2003-2004}

Observations at the buoys and simulated fields lead to the following results. Warm events associated with eastward currents are observed for the following periods: Dec. 12-22, Jan.9-17 (hereafter the 'January event'), Feb. 1-7 (hereafter the 'February event'), March 2-4, and March 10-15. They consist of pulses of a few days with a large day-to-day variability. The simulated surface zonal current and temperature fields are consistent with the observations, although at Peñas the model tends to overestimate the eastward flow. The subsurface fields of temperature and velocities provided by the model are consistent with along shore patterns typical of Navidad events as described in literature. However, the events consist more of 'pulses' with a short duration rather than a well identified event. The existence of pulses has been described by (Pingree and Le Cann, 1990) but to our knowledge, there is no study dedicated to the Navidad event variability at short-time (daily) scales.

\section{What does altimetry detect?}

\subsection{The January and February events}

\subsubsection{Along track signals}

Fig. 10 shows the geostrophic current anomalies (hereafter GCA) variations as a function of time and latitude (from the coast to $44.7^{\circ} \mathrm{N}$ ) along the tracks at the northern Iberian coast (recall that the anomalies are computed with respect to the mean over the year 2004). For all these tracks, an eastward GCA at the coast is depicted, with values between 0.08 and $0.3 \mathrm{~m} / \mathrm{s}$ south of $44^{\circ} \mathrm{N}$ in January and in February (note that there is no available data for J172, J213 and TP248 early February close to the coast). The amplitude and the meridional extension of the signal along the tracks do vary from one track to the other. For instance, the GCA is larger in February on TP172 (reaching $0.32 \mathrm{~m} / \mathrm{s}$ at $43.6^{\circ} \mathrm{N}$ ) than on J96 (reaching $0.13 \mathrm{~m} / \mathrm{s}$ at $43.8^{\circ} \mathrm{N}$ and $44.05^{\circ} \mathrm{N}$ ). Furthermore, the GCA is located more to the north in January than in February: this is clearly visible on tracks TP172 and J96. The differences between tracks can be explained by the difference of the tracks inclination, the difference of the respective dates of the track passage, or a real spatial variability of the intensity of the current as 
observed in the buoy data and in the model. Altimetric data provide extra information with respect to the buoy measurements in that they potentially reveal the meridional extent of the flow and give some spatial context to the currents observed at the buoy locations. For instance, the eastward current vein extends from $44^{\circ} \mathrm{N}$ to $44.30^{\circ} \mathrm{N}$ on track TP137 near Bares, and from $43.6^{\circ} \mathrm{N}$ to $43.8^{\circ} \mathrm{N}$ on track TP172 near Peñas. However, because of the very limited number of satellite SST images available, we cannot assess the value of this information.

The maps given in Fig. 11a provide a full overview of the along-track GCA for the periods Jan. 12-18 and Feb. 1-7, superimposed with SST from the CMS dataset. The eastward flow along the northern Iberian coast is clearly visible, as well as the large variations in amplitude and direction along the coast. For the two periods, we can identify areas of acceleration, located around Cabo Ortegal (near Bares, $\sim 8^{\circ} \mathrm{W}$ ) and around $3.5^{\circ} \mathrm{W}$, probably the signature of eddies trapped by topographic irregularities. Indeed, the GCA variations along the track J96 shown in Fig. 10 depict a dipole structure typical of an eddy on Jan.12.
4.1.2. Comparison with current measurements from buoys

The altimetric GCA are compared to the equivalent across-track velocities of the surface current observed at the buoys (Fig. 12). For comparison, we average the altimetric GCA over the three closest points of the two neighbouring tracks to each buoy. The equivalent across-track velocities are computed by projecting the total current measured at the buoy onto the direction perpendicular to the tracks. In other words, at Bares the buoy current is projected onto the directions perpendicular to J96 and to TP137 (so we obtain two velocity estimates); at Peñas, the tracks are TP172 and J137 and at Villano there is only track TP96. At last, we compute the anomalies by removing from the velocities their mean over the year 2004 (as for the altimetric GCA). The blue curves in Fig. 12 indicate the zonal component of the observed current anomaly at the buoy.

In Fig. 12, we obtain a good agreement between the estimates from altimetry and from the buoy data for the amplitude and sign. At Bares, data from $\mathrm{J} 96$ (in red) tend to fit the buoy time series better than data

\section{a. 13101104}

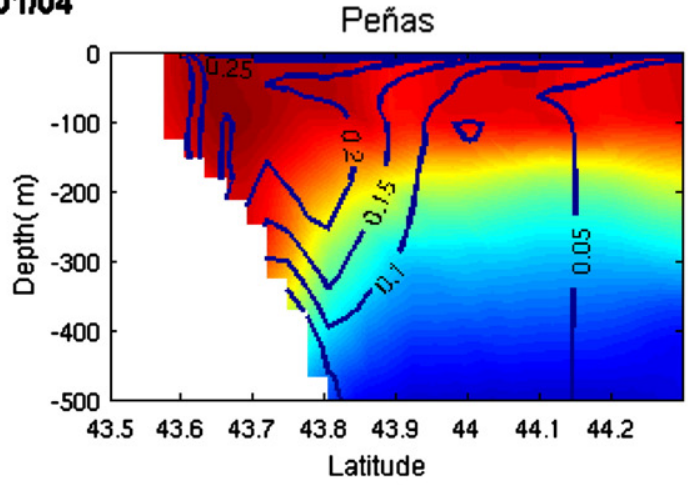

\section{b. $01102 / 04$}

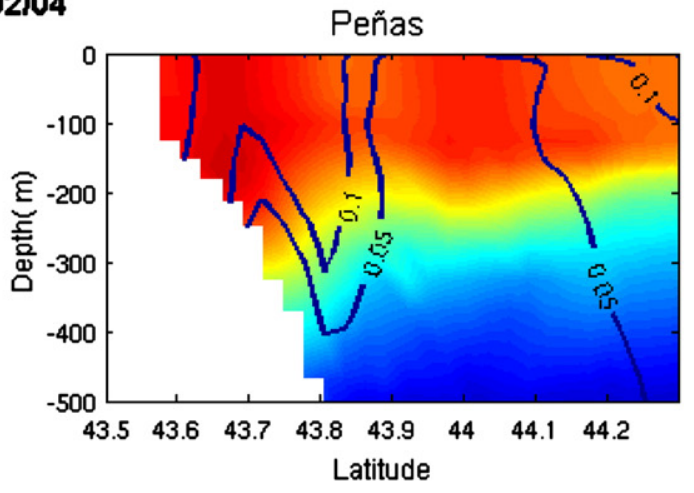

\section{C. $27 / 10 / 04$}

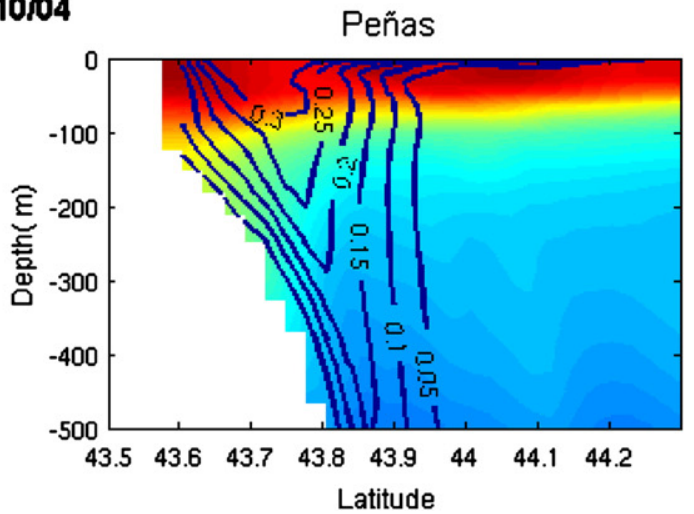

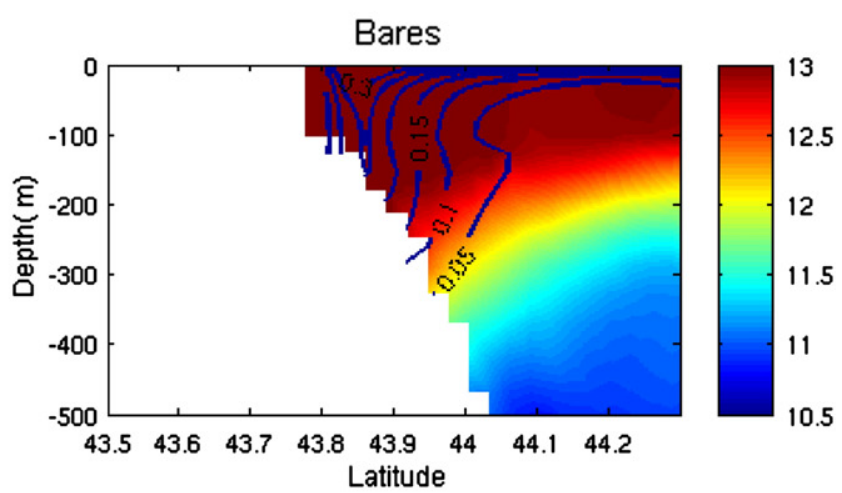
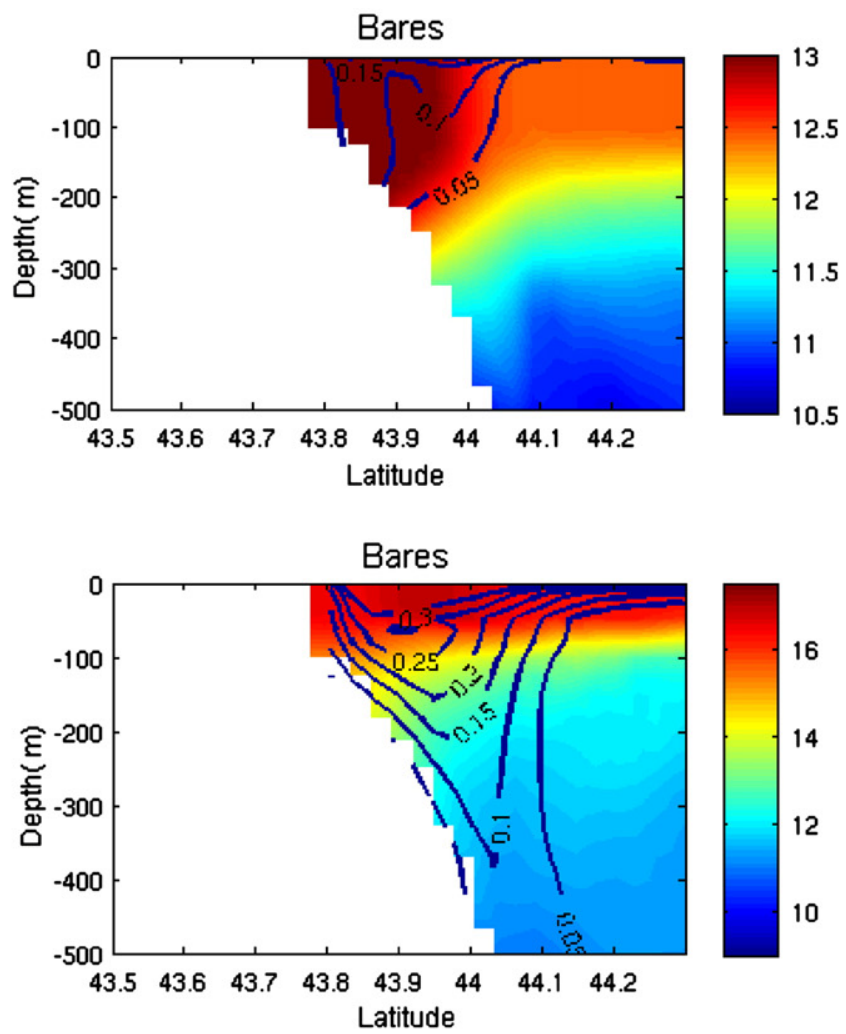

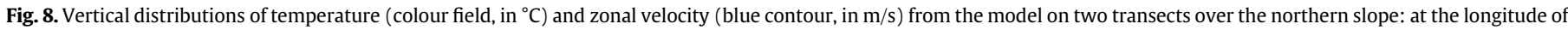

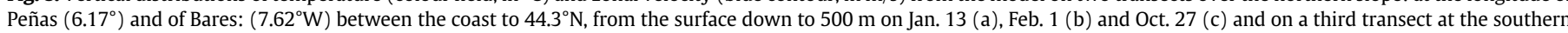
open-boundary $\left(43.29^{\circ} \mathrm{N}\right)(\mathrm{d})$. 


\section{d. Open-boundary}
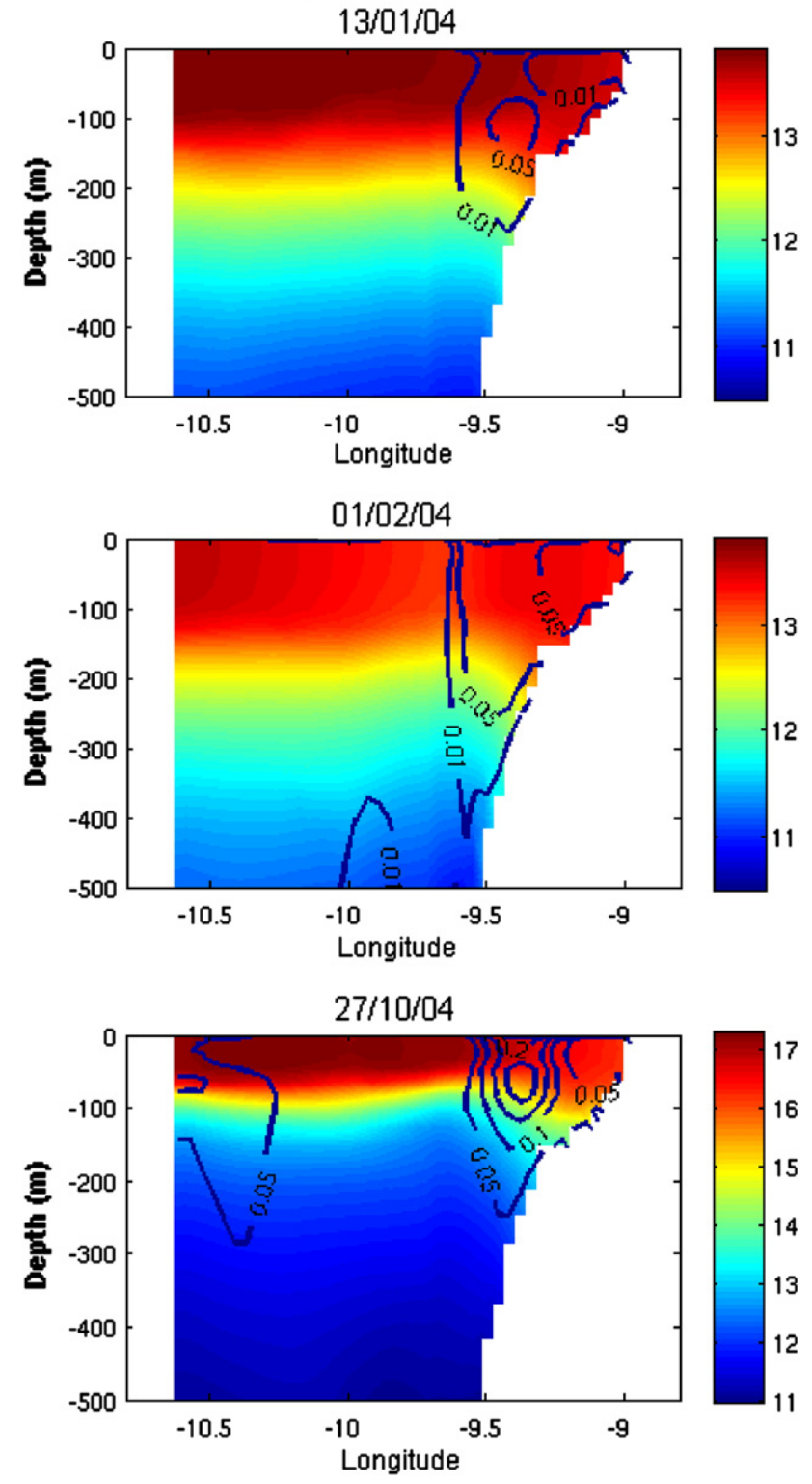

Fig. 8 (continued).

from TP137 (in green). For the February event, they both give remarkably close values to the buoy data; the agreement is also good before and after the event, but TP137 GCA overestimates the current variations. Close to Peñas, larger differences are obtained between the track J137 and TP172 estimates, with cases where the GCA sign is different (e.g. in mid-February and late March). For the February event, TP172 indicates eastward anomalies, whereas J137 suggests weak westward anomalies instead. Unfortunately, there is no buoy data available over this period. Finally, close to Villano, the GCA from TP96 is in good agreement with the buoy data during the eastward pulses. In early January, the GCA as estimated from the altimetric data is in good agreement with the current anomalies observed at the buoys, with better agreement for J96, TP172 and TP96 than for TP137 and J137. Note that T/P172, T/P96 and J96 are descending tracks, meaning that the measurements are less affected by the presence of land than on the ascending tracks (TP137, J137).

The GCA misfits between neighbouring tracks and cycles are not well understood. Part of it is due to real high-frequency variability ( $O$ (1 day)), that is large in coastal areas and that may be underestimated in the model. But it is due as well to errors in some geophysical corrections (for example, the tropospheric humidity effects and sea state bias). The errors or uncertainties on such corrections are known to be enhanced in coastal areas, due for example to a land contamination of satellite measurements or to a lack of resolution in the data (e.g. Andersen and Scharroo, 2010; Obligis et al., 2010). They are also probably larger in the high-frequency band. As some corrections are not estimated using the same instruments in TP and J1 data, these errors are expected to be different for the two datasets. Exploring the impact of the different correction uncertainties on the signal consistency in this data set is beyond the scope of this paper. The objective here is to evaluate the information content of the present altimetric coastal dataset and to identify further issues to address.

\subsection{Comparison between altimetric and simulated SLA signals}

We compute the model SLA by removing from the simulated sea surface elevation its mean over the year 2004. We then build synthetic altimetric observations by sampling the simulated SLA at 
Surface meridional current $(\mathrm{m} / \mathrm{s})$

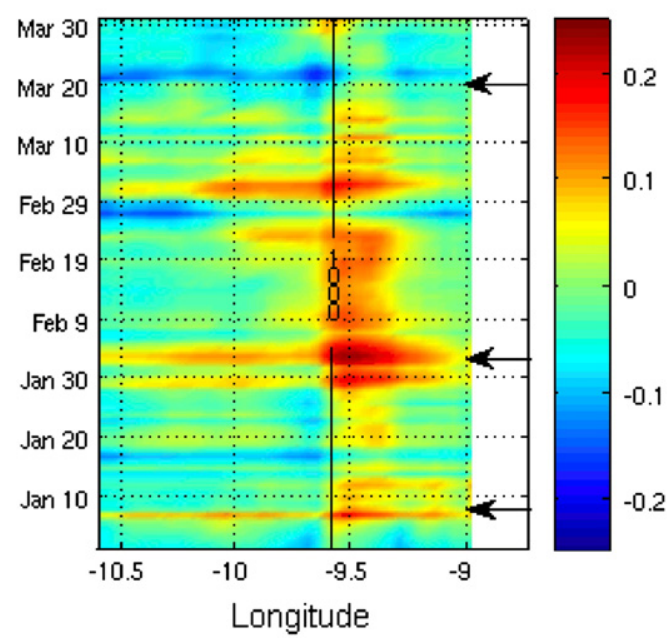

Meridional current at $127 \mathrm{~m}(\mathrm{~m} / \mathrm{s})$

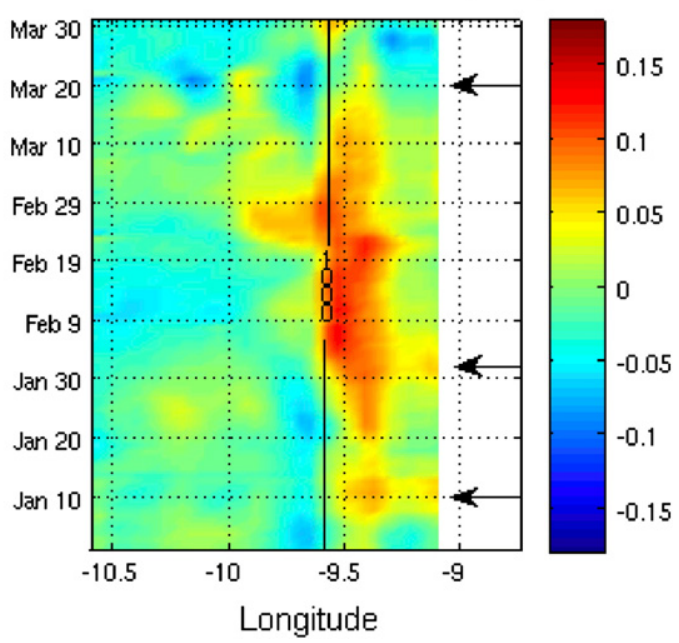

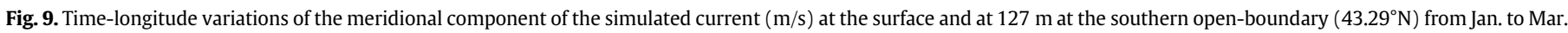
2004. Positives values indicate northward current. The isobath $1000 \mathrm{~m}$ is indicated by the thin black line.

the same points and days as the real data. For comparison, the same map presented in Fig. 11a is made but with synthetic tracks from the model (Fig. 11b). As observed in altimetric data, an eastward flow is clearly visible along the northern Iberian coast but with lower amplitude in the model than in altimetry. In January, altimetric and simulated signals are consistent whereas in February the model data agreement is poorer. The consistency at the crossover points is not systematically better in the model than in the data. Model-data misfits on the dates of occurrences can be expected partly because of inaccuracies in the open-boundary conditions as well as in atmospheric forcing fields.

Besides, as observed in altimetric data, some intensification of the current can be noticed around $3.5^{\circ} \mathrm{W}$ and to a lesser extent around Cabo Ortegal $\left(\sim 8^{\circ} \mathrm{W}\right)$. The SLA fields from the model suggest that the intensification is the signature of oceanic eddies. Indeed, the eastward flow along the continental slope is known to develop numerous eddies which interact with the topographic irregularities such as the Cabo Ortegal or the Santander Canyon $\left(\sim 4^{\circ} \mathrm{W}\right)$. These typical eddies are called swoddies (Slope Water Oceanic Eddies, e.g. Pingree and Le Cann, 1992; Garcia-Soto et al., 2002). The observation of oceanic eddies in altimetric data and in the model raises the question of the impact of the mesoscale on the eastward circulation along the northern Iberian coast. A misrepresentation of the intensity or position of the eddies in the model could locally generate a bias between the observed and simulated GCA.

In Fig. 13, we compare the simulated SLA with the same time sampling as the altimetry ( 10 days) and the SLA from altimetry along the same track (TP172). The model shows a good agreement with the SLA variability close to the coast, especially for the January and early February event. From mid-February, the model indicates a shift offshore of the SLA gradient, consistent with what is observed for the surface and subsurface current (Figs. 5 and 7). On Feb 24, an SLA gradient at the coast corresponding to a westward anomaly is seen in both model and data. On March 5, the slope signal in the model and in the altimetry is located further from the coast, and tends to move closer on March 15. However, the signal in the model is closer to the coast than in the data and its amplitude is significantly weaker. In order to determine whether the time sampling of altimetry is suitable for the study of high frequency of this current at high frequency, Fig. 13 also compares the daily SLA signal along the synthetic track TP172 in the model with the signal sampled every 10 days as in altimetric observations. It suggests that the 10-day repeating cycle allows the main events to be detected. Pulses with a shorter duration (a few days) can be missed such as in January or March, but the use of several consecutive tracks may allow us to recover partly the high-frequency variability.

Note that we have checked the relevance of using daily-averaged current estimates from the model to compare with along-track altimetric data which represent a 'snapshot' of an (almost) instantaneous state of the ocean. The results indicate that the use of instantaneous outputs from the model (requiring a tremendous volume of simulation archives) does not bring any significant improvement. As simulation inaccuracy and satellite observation defects are likely to be mostly concentrated in the high frequency band, using a daily averaged output may provide a better estimate than a snapshot at the same time of the day than the observation.

\subsection{The October event}

The October event is distinct from the January and February ones in the sense that it is not associated with any obvious SST signals. The analysis of satellite images does not therefore allow us to identify any circulation pattern over the period (see Fig. 2 for Oct. 22). Measurements from buoys (Figs. 4b and 14) indicate a surface eastward flow with speeds greater than $0.2 \mathrm{~m} / \mathrm{s}$ (up to $0.3 \mathrm{~m} / \mathrm{s}$ on Oct. 26 at Bares). The current pulses are associated with strong northward or northeastward wind occurrences (Fig. 4b): see for instance on Oct. 8-10.

Consistently with the satellite observations, the model simulation does not display any warm surface tongue along the northern Spanish coast (not shown). Although the model tends to overestimate the intensity of the current, eastward pulses are simulated at dates consistent with the buoy observations (Fig. 14). The vertical sections from the model on Oct. 27 (Fig. 8c) show an upper slope current vein, about $25 \mathrm{~km}$ wide at the open-boundary and along the northern Iberian coast. The eastward vein is associated with a subsurface warm anomaly with temperature up to $13.4^{\circ} \mathrm{C}$ at $200 \mathrm{~m}$. At the openboundary (Fig. 8d), we observe a vein of warm water reaching $17.4^{\circ} \mathrm{C}$ and extending over the first $50 \mathrm{~m}$.

The altimetric GCA variations along the tracks shown in Figs. 10b and 11a clearly depict a signal at the coast in mid and late October. Over the whole Sep.-Nov. 2004 period, the agreement between the altimetric GCA and the surface zonal current anomalies at Bares is very good, except for two dates in September and November with an overestimation of the TP137 GCA. In particular, the J96 signal represents the current variability during the October event. The agreement is also relatively good at Peñas, but larger misfits are observed in November (Fig. 14). 
a
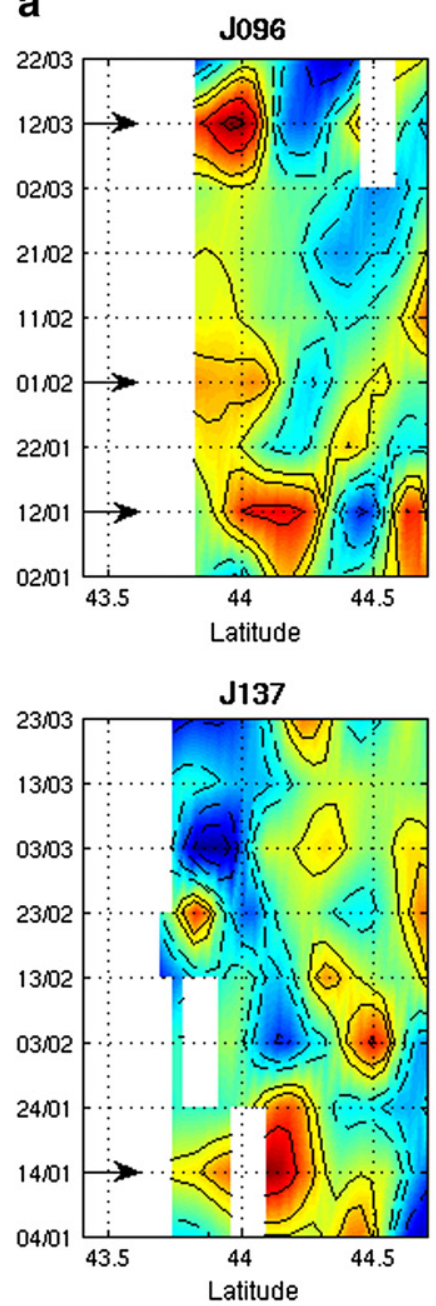

b

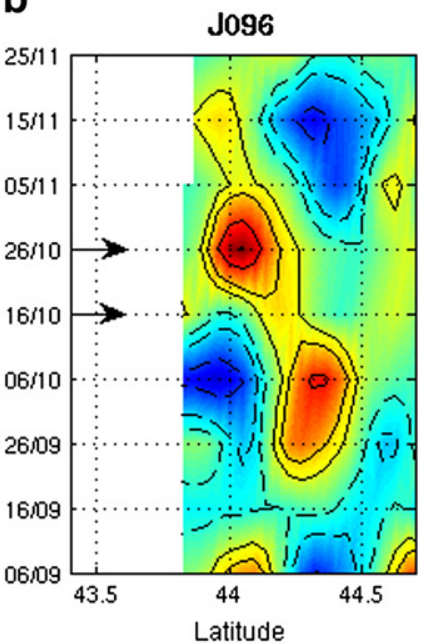

TP137

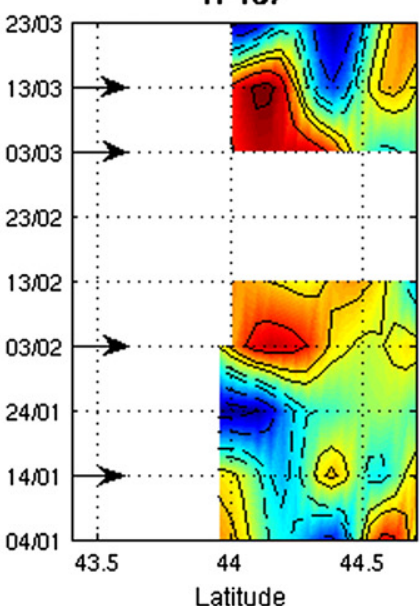

TP172

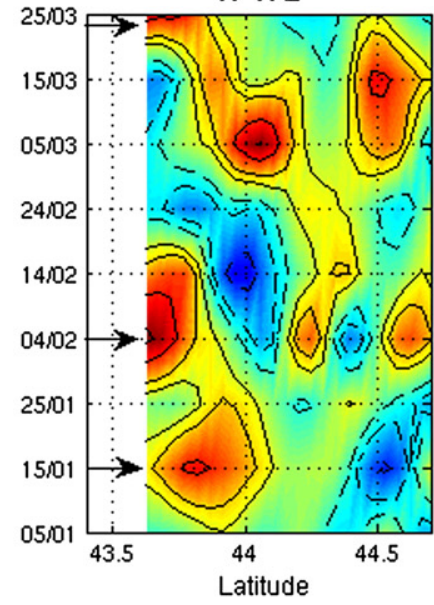

J1137

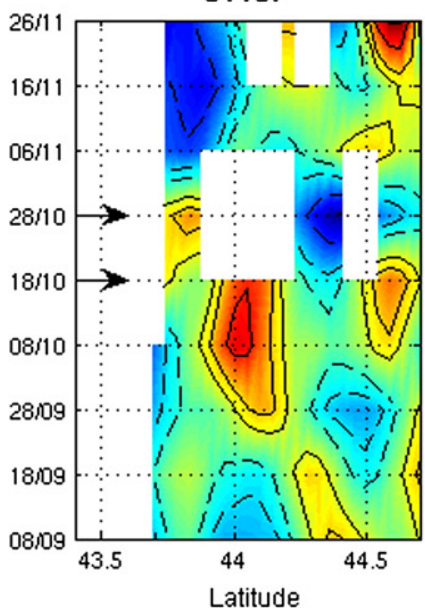

J172
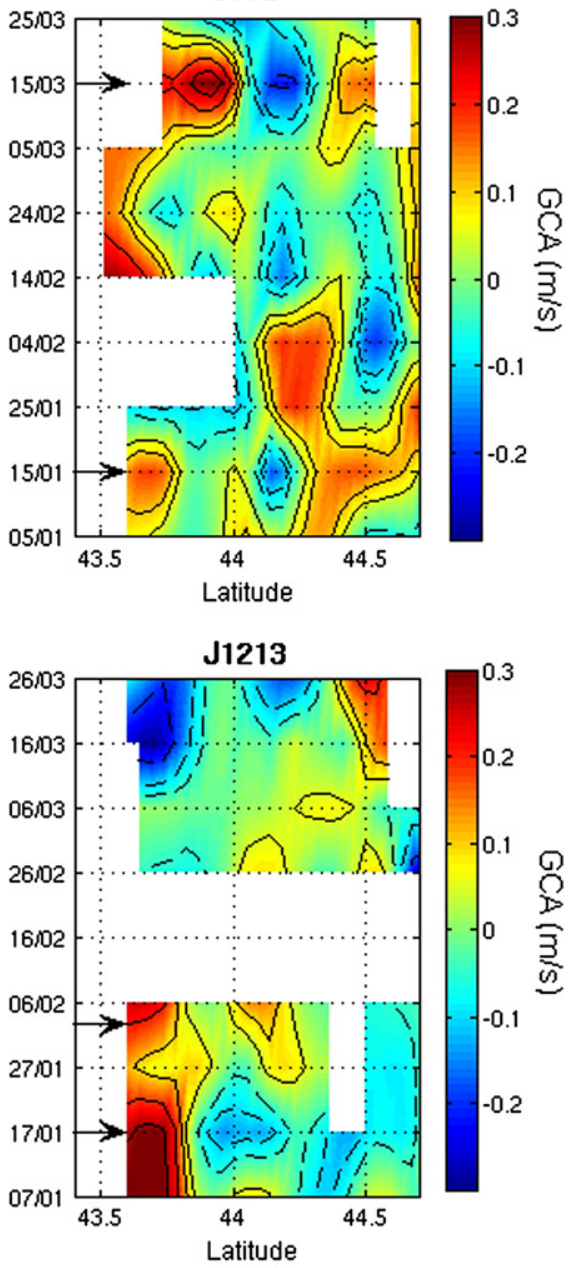

TP172

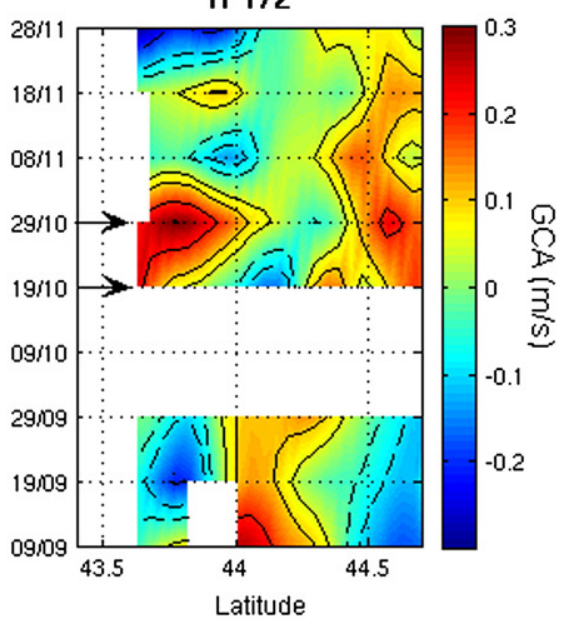

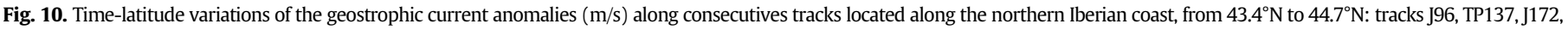

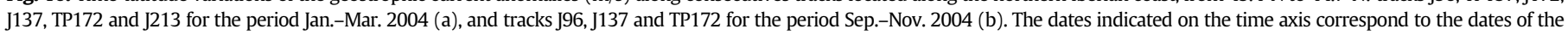

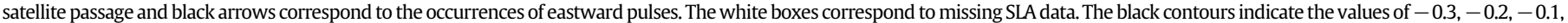
-0.05 (dotted line) $+0.05,+0.1,+0.2$, and $+0.3(\mathrm{~m} / \mathrm{s})$ (solid line). Recall that J96 and TP137 intercept the coast near Bares, TP172 and J137 near Peñas, and TP96 near Villano.

The event of October 2004 is an interesting case as it can illustrate further the benefit of using altimetric data. In this example where no clear SST signal is observed, we have shown that the altimetric data allow us to identify a slope current with warm subsurface anomalies that can be considered as an intrusion of the IPC into the Bay of Biscay.

\subsection{Geostrophic circulation near Bares}

We use the model to better understand the geostrophic signal as revealed by altimetry. From the simulated SLA, we can compute different estimates of the geostrophic current anomaly (GCA): the zonal and 
meridional components and the along-track component (thus in the across-track direction). Fig. 15 shows the time variations of the zonal GCA at $7.62^{\circ} \mathrm{W}$. The geostrophic vein is located south of $44^{\circ} \mathrm{N}$, within the first $500 \mathrm{~m}$, whereas, not surprisingly the ageostrophic component has larger meridional scales. We note that the geostrophic pulses are correlated in time with the ageostrophic ones at least during the eastward events. The correlation between geostrophic and Ekman dynamics in this area is due to the vicinity of the coast. Indeed, during westerlies or south-westerly wind events, the Ekman current tends to be eastward. Besides, the derived Ekman transport towards the coast tends to generate a sea level slope at the coast that in turn, by geostrophy, enhances the eastward surface current.

Fig. 15 shows that the Bares buoy is located at the edge of the eastward GCA vein. Close to the coast however, the simulated along-track GCA are in closer agreement with the total zonal current at $50 \mathrm{~m}$ than for the equivalent surface current (Fig. 16). These figures suggest that at the buoy location the simulated geostrophic current is weaker than close to the coast. In Fig. 17, we compare the geostrophic velocities from the altimetric data with two estimates from the model along the synthetic tracks: for the first estimate we average the model along-track velocities over the three

\section{a. Altimetry}

\section{Date: Jan $15+1-3$ days}

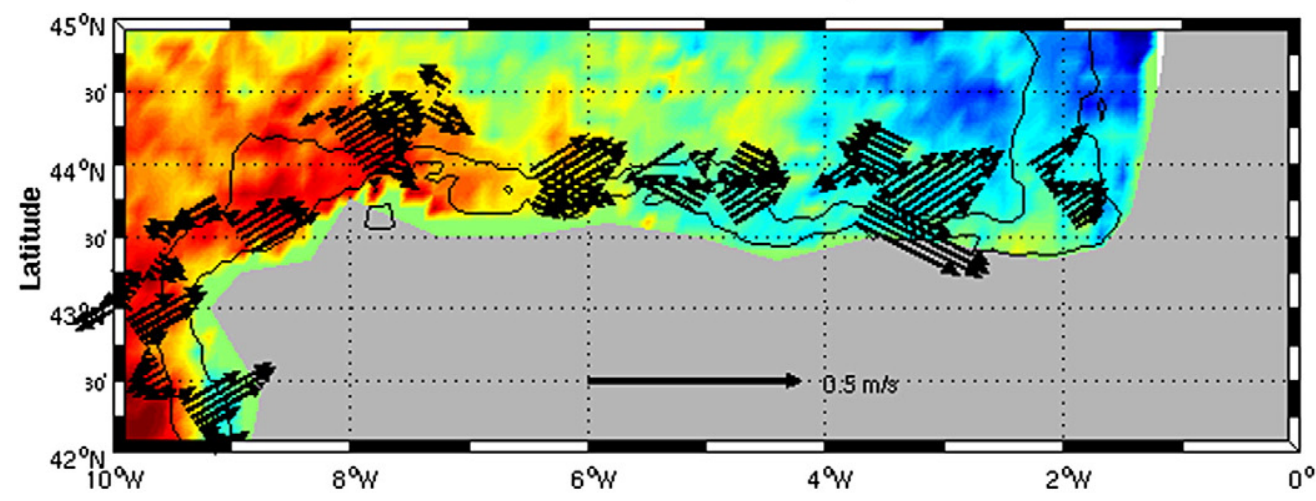

Date: Feb $4+1-3$ days

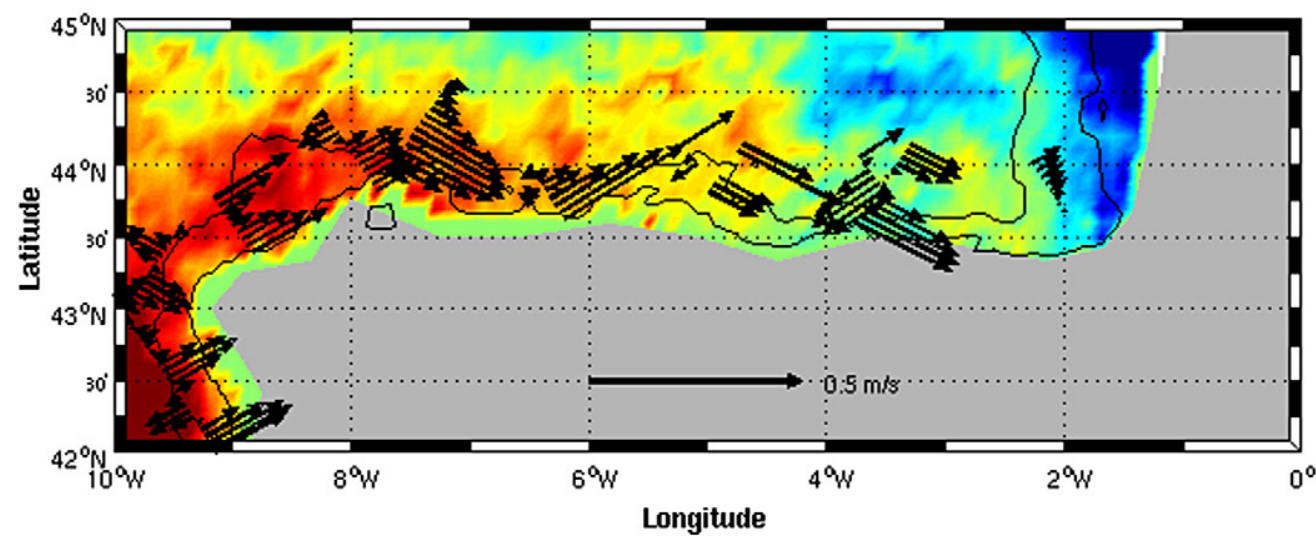

Date: Oct $28+1-3$ days

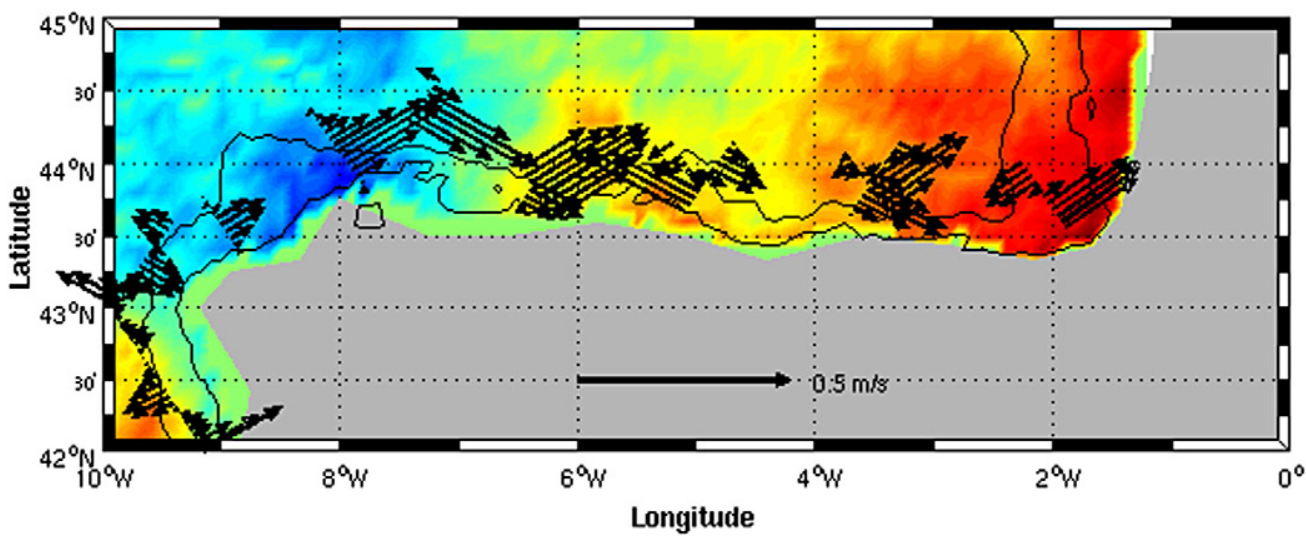

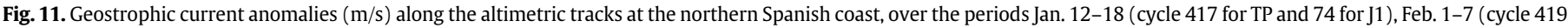

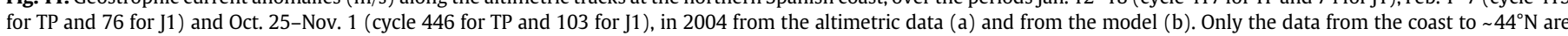
shown. The colour fill (in ${ }^{\circ} \mathrm{C}$ ) shows the surface temperature from Météo-France CMS dataset respectively on Jan. 18, Feb. 2 and Oct. 27.
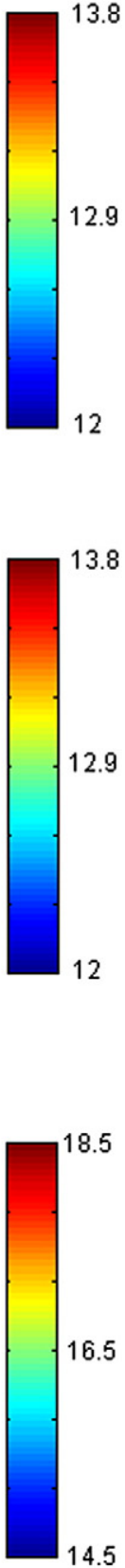

2.9 


\section{b. Model}

\section{Date: Jan $15+/-3$ days}
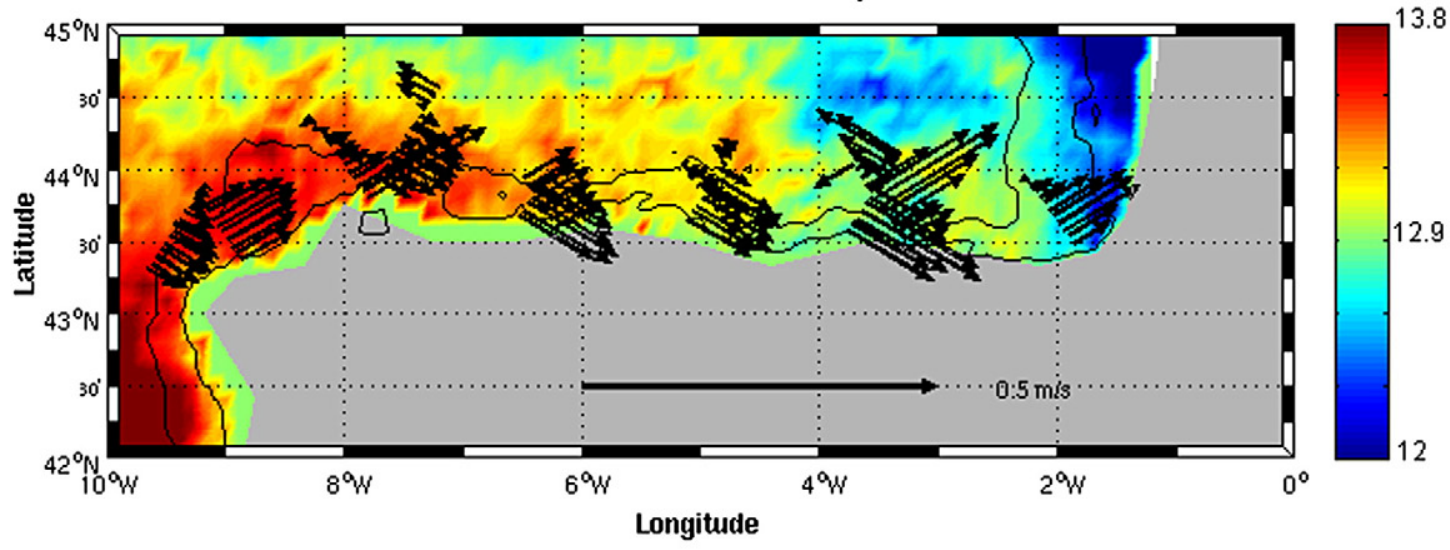

Date: Feb $4+1-3$ days
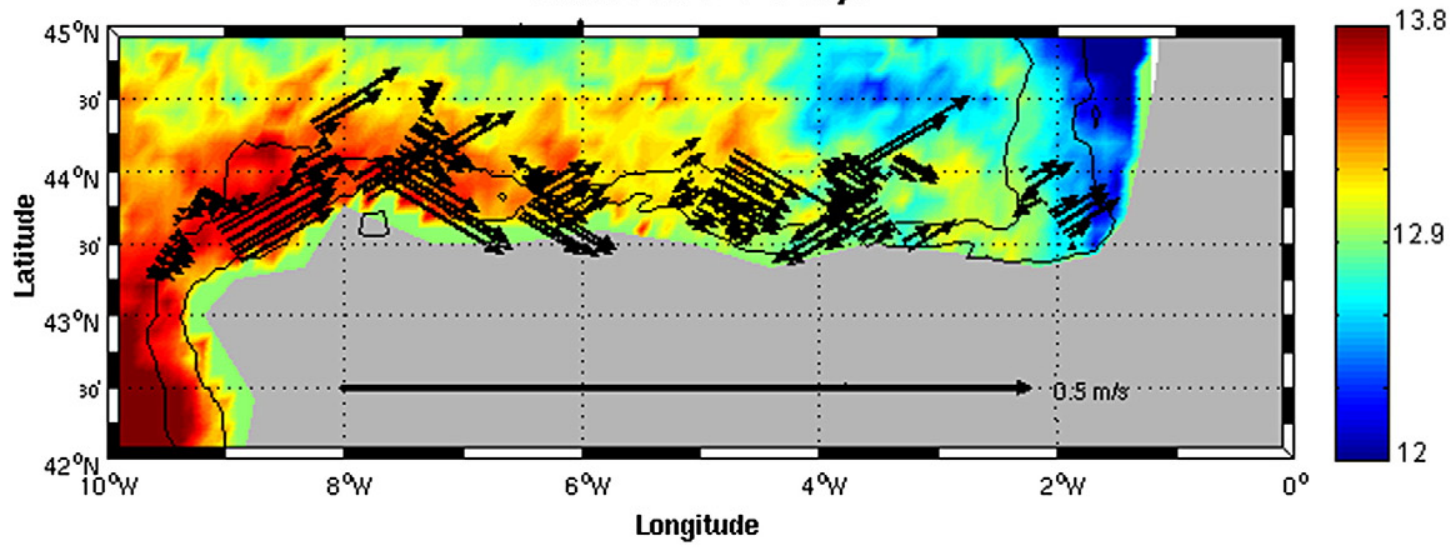

Date: Oct $28+1-3$ days
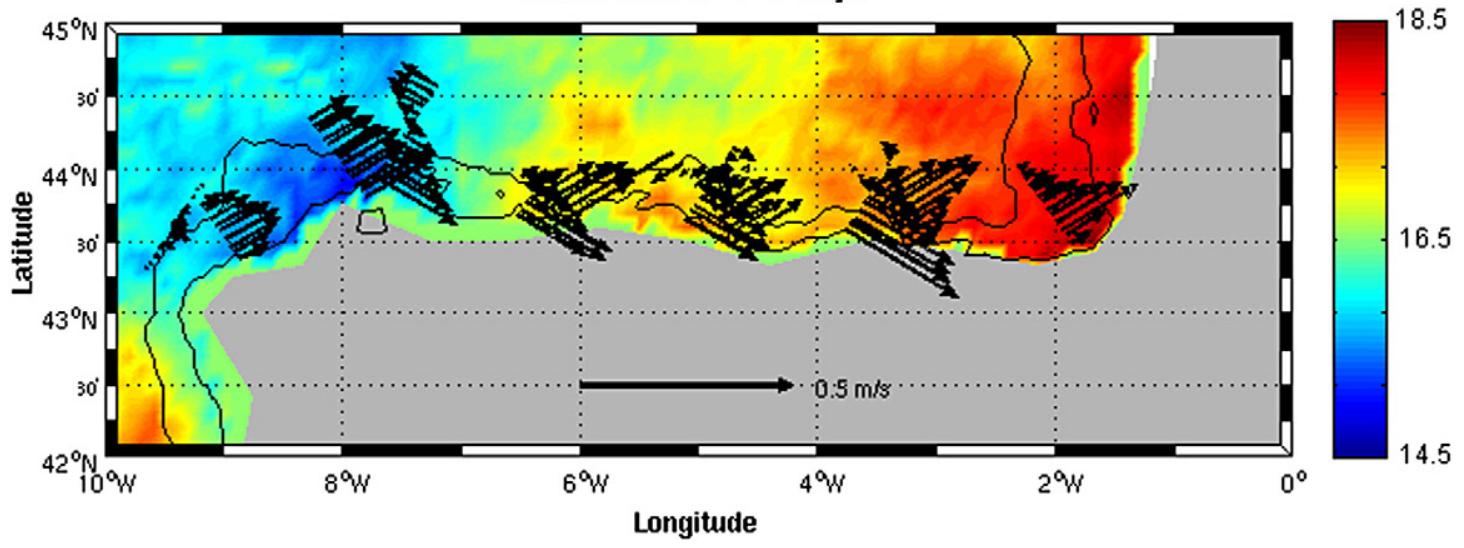

Fig. 11 (continued).

closest points to the Bares buoy, for the second one we compute the average over the three closest points to the coast along the synthetic tracks. The agreement with the altimetric velocities is much better with the second estimate. One explanation is that the model tends to simulate the eastward geostrophic current much closer to the coast than it should be, for this location. The smoothing of the model bathymetry with a shelf that is too narrow would be responsible for this bias. The same kind of bias is found by Otero et al. (2008) when comparing their model velocity with the one measured at the Cabo Silleiro buoy.

On the other hand, we find, according to the model, that the geostrophic component of the zonal current is weak at the Bares buoy, but at the same time, both the altimetric current and the model total surface current at the buoy location are consistent with the in situ observed surface velocity. An explanation for this apparent contradiction is that the altimetric signal is spread offshore (because of the data sampling mainly) and the across-track GCA is overestimated at the buoy location. The good correlation between the surface current anomaly as observed at the buoy and the altimetric GCA in Fig. 12 would then be due to the correlation between the geostrophic and Ekman flows.

In conclusion combining the information from the model, the current at the buoy and the altimetric data in the area of Bares led us to two possible interpretations. In the first one, the altimetric signal near Bares is spread too much offshore leading to an overestimation of the geostrophic current at the buoy location. The second one considers that the simulated current is located too close to the coast, likely because of the bathymetry smoothing. Both interpretations are probably true, with a small bias in 

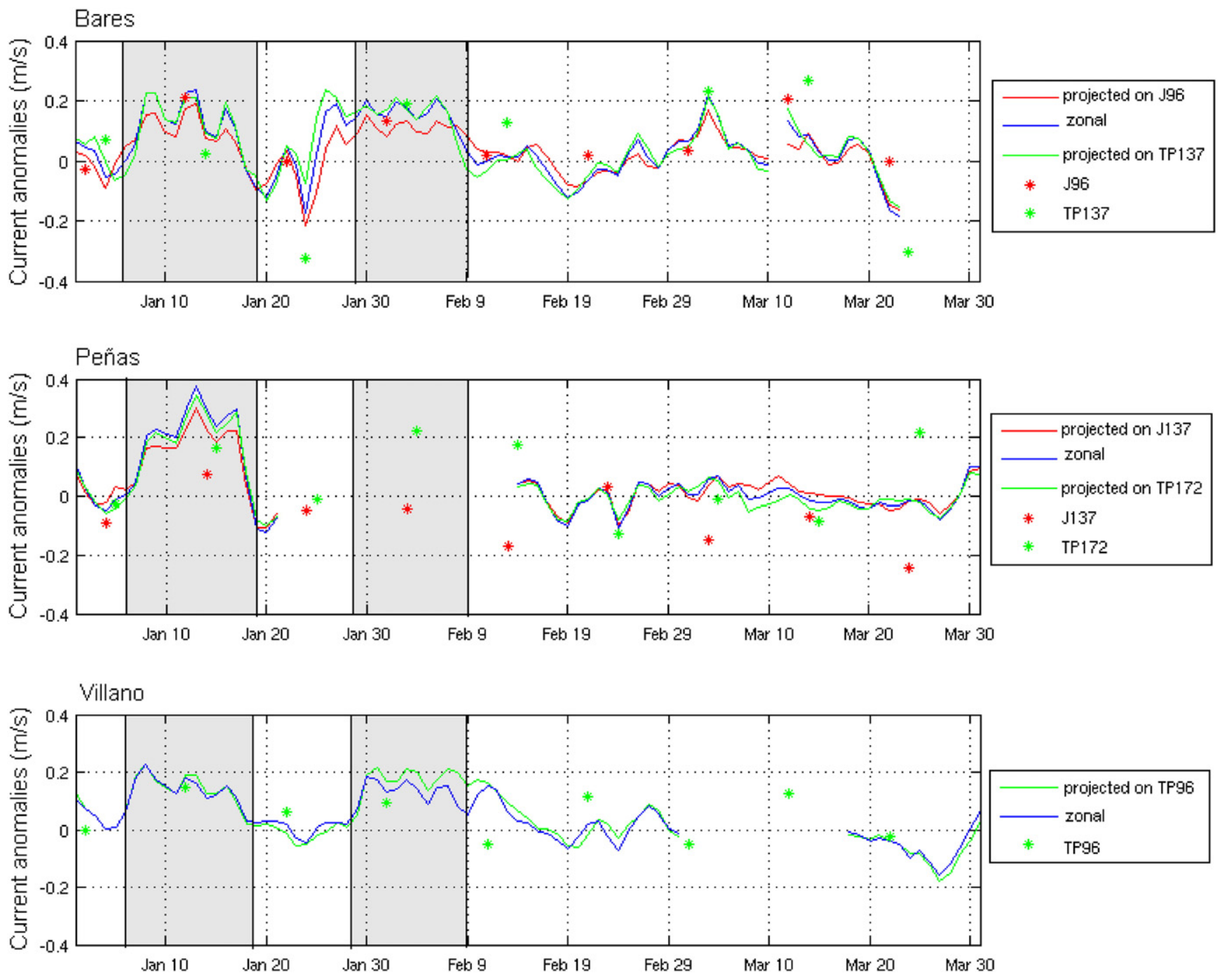

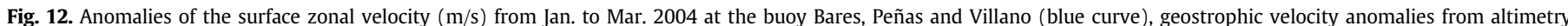

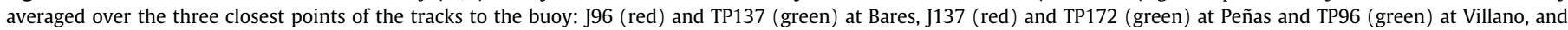

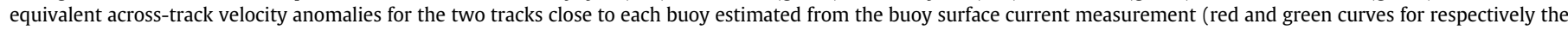
projection on the Jason and TP tracks).
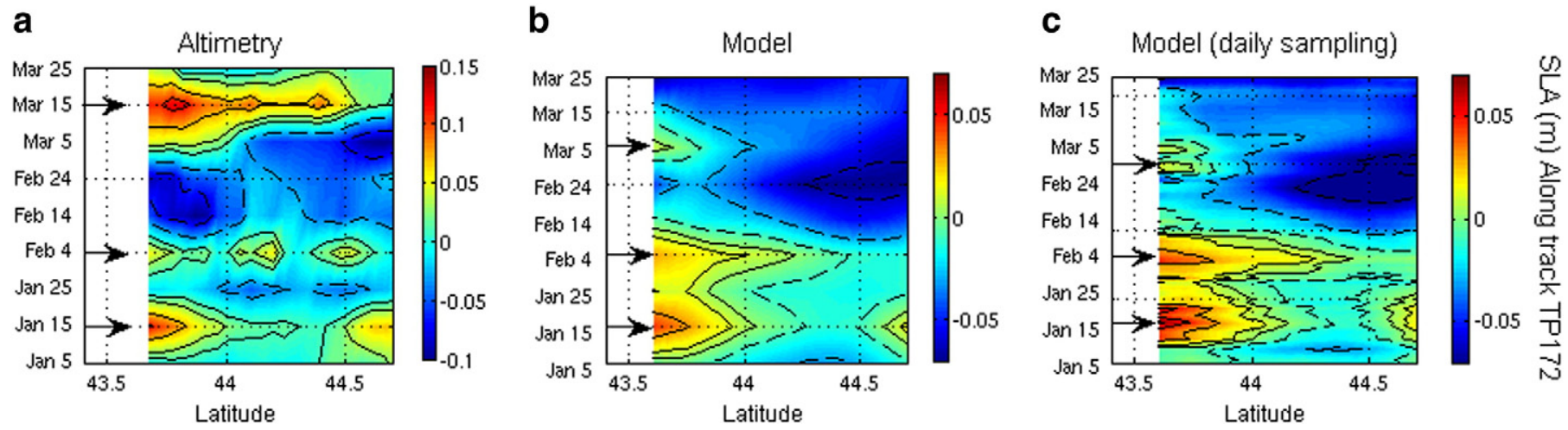

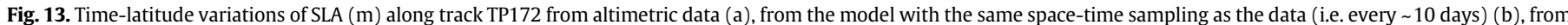

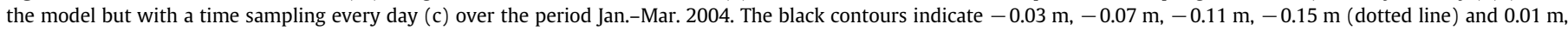

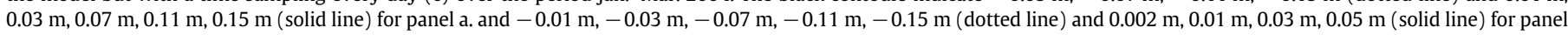
b. and c. Note that the colour scale is different for the model and the observations. 

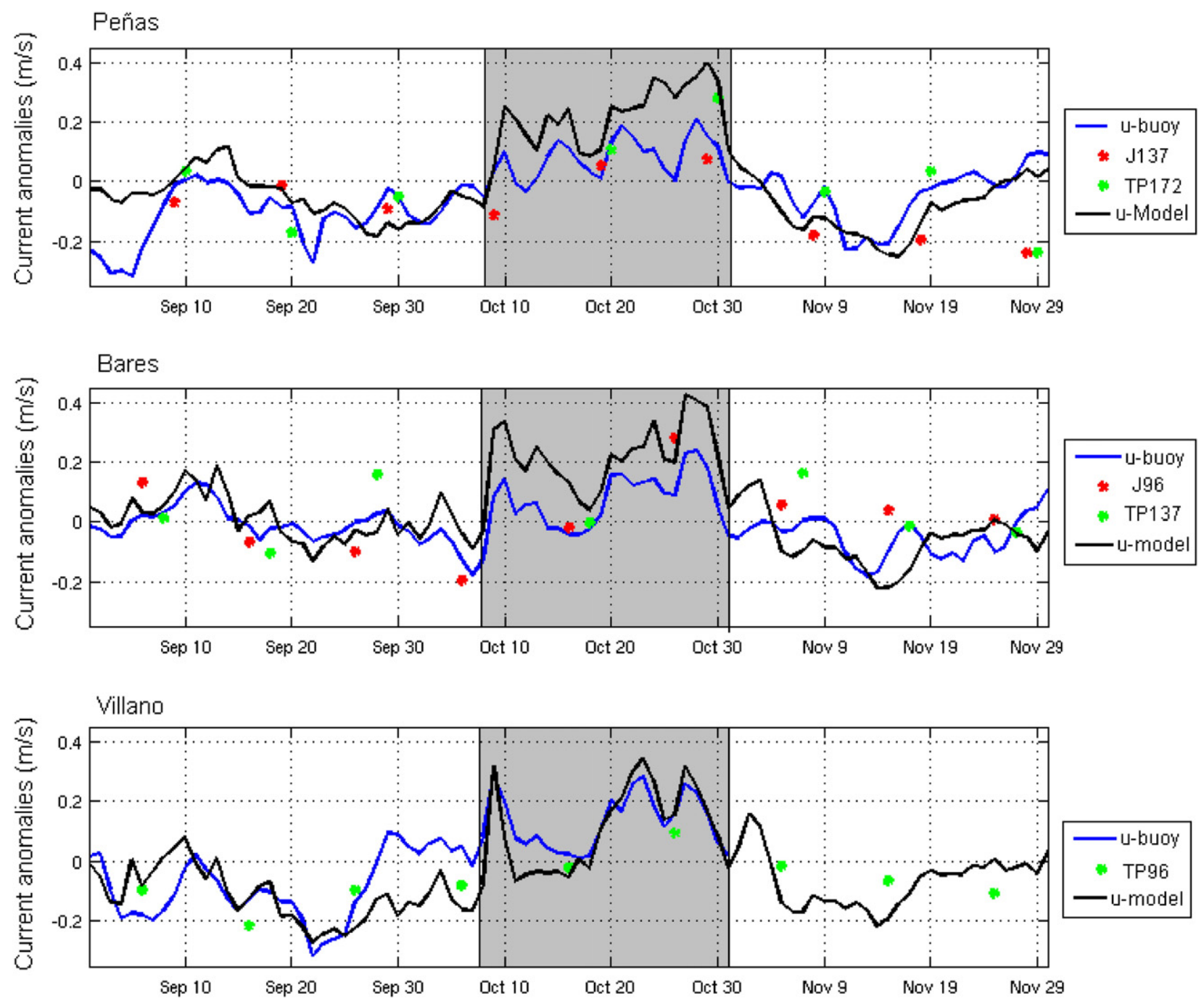

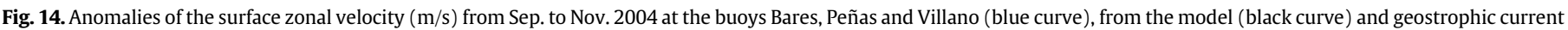

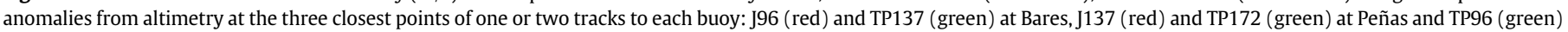
at Villano.

both the model and altimetric estimates. These results stress the need for additional in situ data, including typically subsurface hydrological and velocity measurements at the buoy. These additional observations would allow for a better understanding of the surface current observed at the buoys.

At Peñas, the situation is slightly different: the buoy is located in the main geostrophic vein - according to the model. However, the total surface current is overestimated in the model with respect to the measurement and over the Feb. 15-Mar. 15 period the altimetric data are closer to the buoy data.

\section{Conclusion}

In this paper, we aim to identify the signature of the circulation over the slope in the southern Bay of Biscay in a coastal altimetric dataset during the winter of 2004 . The use of altimetric data, with a regular, continuous sampling and a large cover over a large area, constitutes a new approach in the study of the coastal high frequency variability of the circulation in this area.

First, an overview of the general surface circulation over the period Dec. 2003-Jan. 2004 is given from the analysis of SST data and surface currents at four buoys, as well as of surface winds at the buoys. Occurrences of a surface poleward flow are clearly depicted between $\sim 42^{\circ} \mathrm{N}$ at the western Iberian coast and $\sim 6^{\circ} \mathrm{W}$ on the northern Iberian coast. They are associated with warm surface anomalies. The observations suggest a large variability in space and time of the current that appears more as pulses over several days than a continuous current over a few weeks. The wind is also highly variable in time: episodes of northeastward winds usually coincide with the eastward pulses along the Iberian coast. We interpret these events as developments of the Iberian Poleward Current and its intrusions into the Bay of Biscay. The intrusions are however limited to the westernmost part of the Iberian coast. Even if the term 'Navidad event' may not apply to the winter of 2004 situation, evidence is found of short-time 'IPC events'. We analyse two events in more details, one in January and one in February, using the SYMPHONIE model simulation and the altimetric data.

Comparisons between the geostrophic current anomalies estimated from altimetry and zonal surface current at the buoys show that the altimetric data is able to detect the main events. The dates and amplitudes are consistent, with some exceptions, mainly at the buoy Peñas. The circulation patterns seem to be influenced strongly by local bathymetric or wind features there. The differences between the velocity anomalies estimated from observations at the buoys and from altimetric data may have several causes. In particular, the current measured directly at the buoys includes the geostrophic and ageostrophic components (as Ekman current) whereas altimetry 

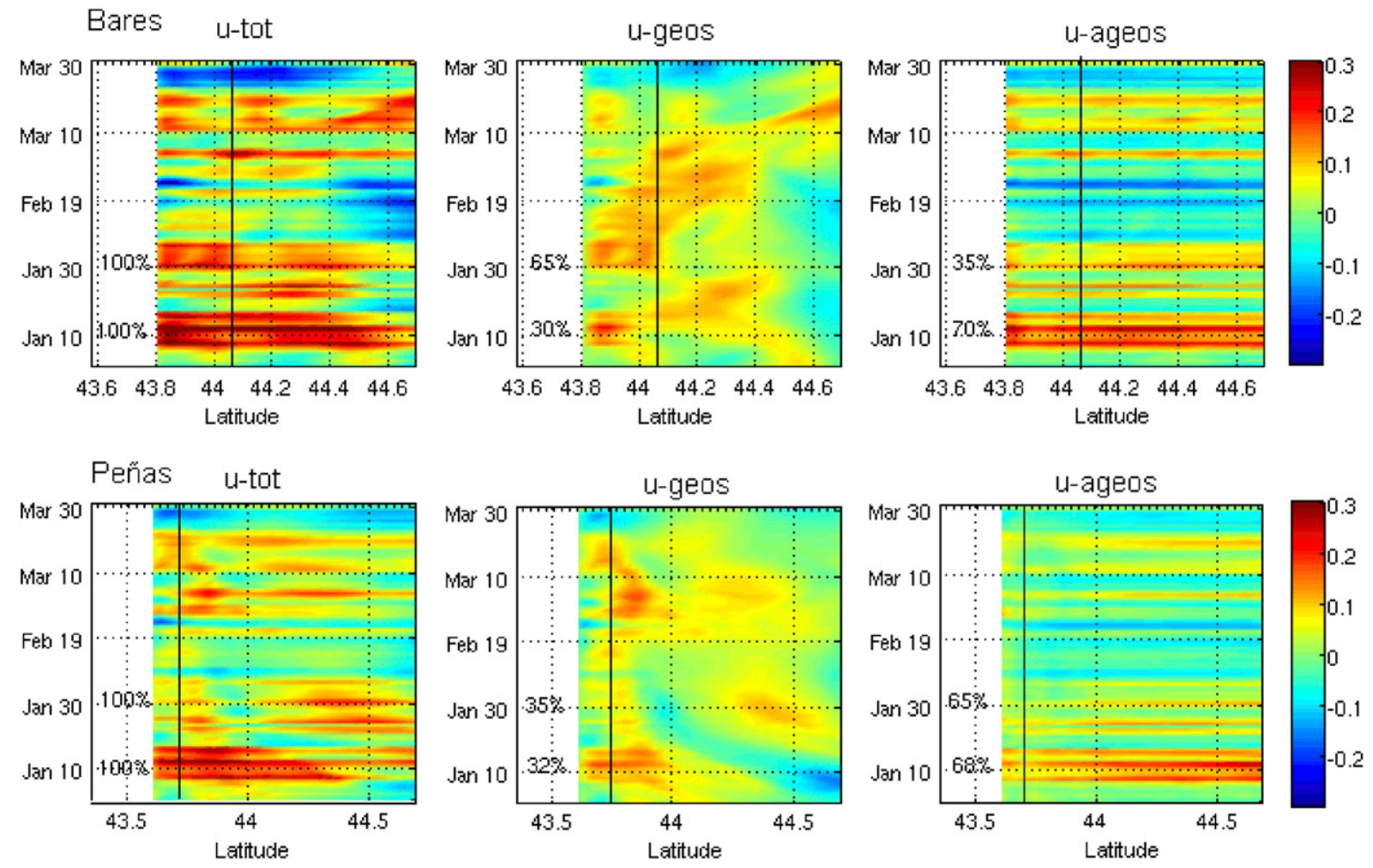

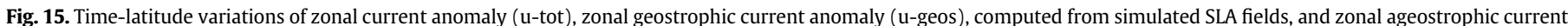

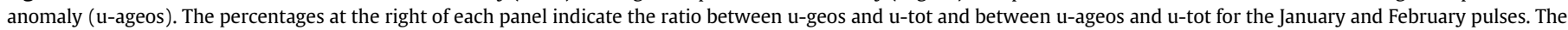
black line indicates the location of the buoy in the model.

gives access only to the geostrophic component. As a consequence, we cannot obtain a quantitative estimate of the uncertainty in the altimetric signal. Additional in situ data are necessary for a better understanding of the observed differences between the buoy and altimetric measurements. Significant differences are observed between the altimetric signals at neighbouring tracks for a few cycles.

a

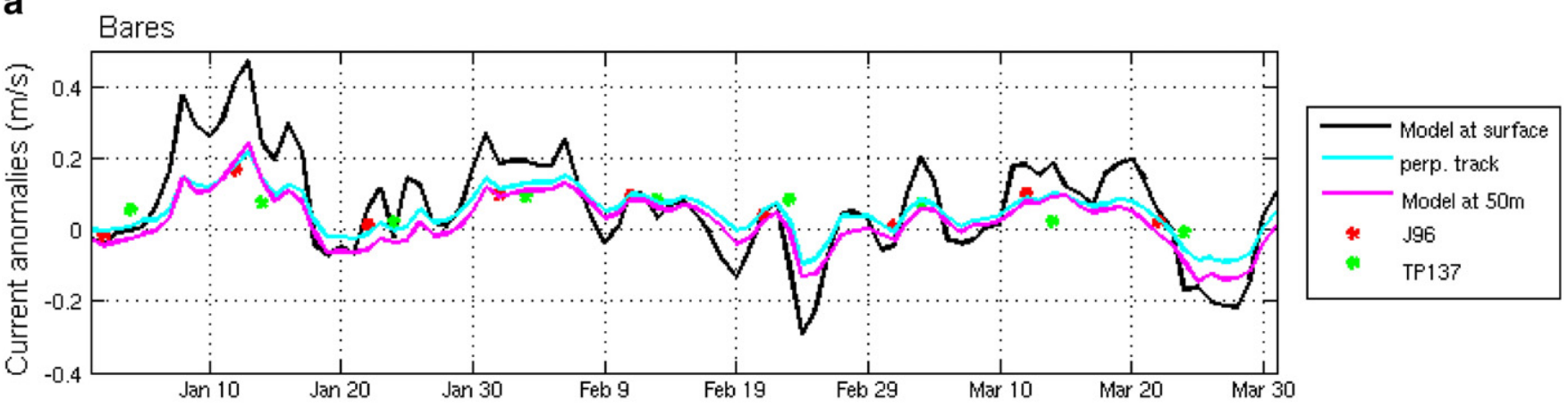

b

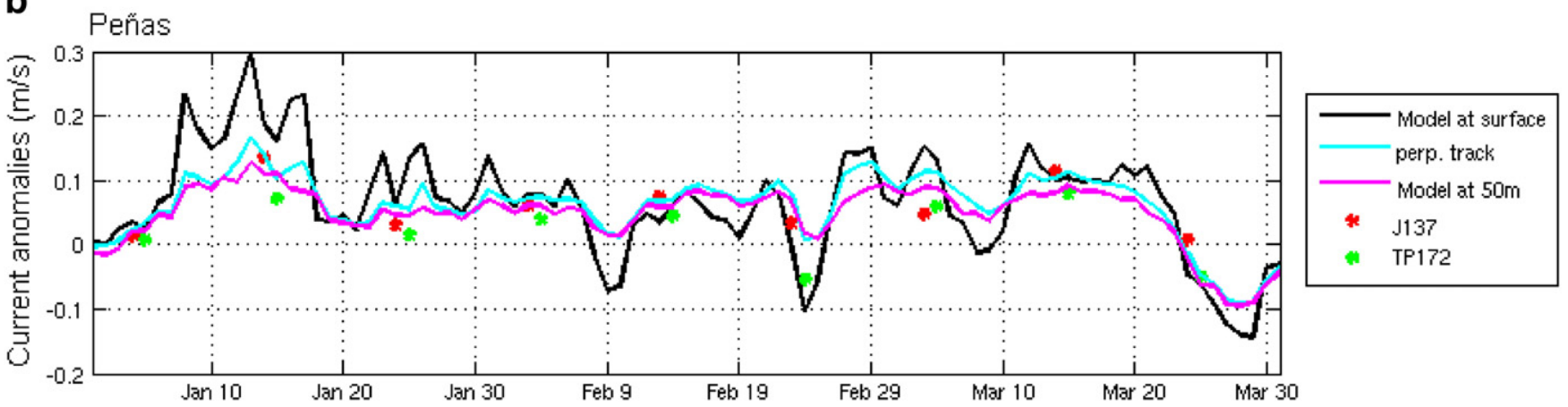

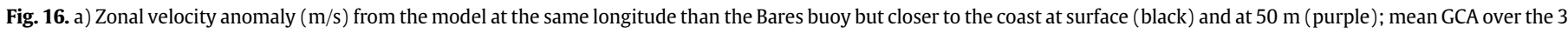

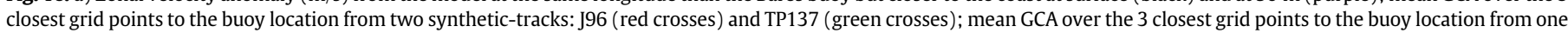

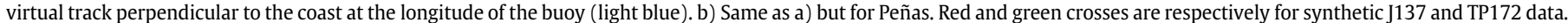


a

Current anomalies from the buoy — , J96 from altimetry * and from the model (closest point to the buoy) *

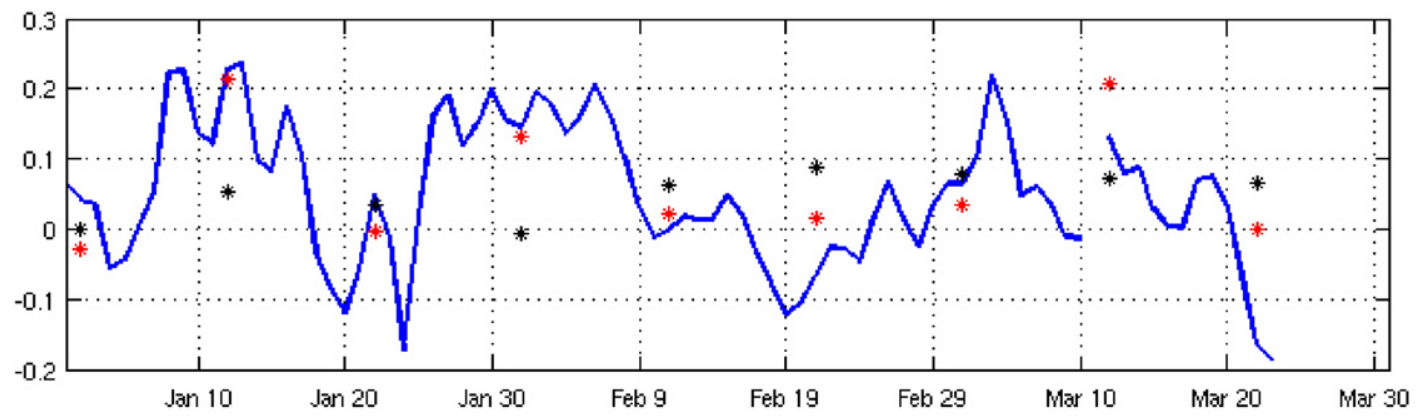

b

Current anomalies from the buoy — , J96 from altimetry $*$ and from the model (closest point to the coast) *

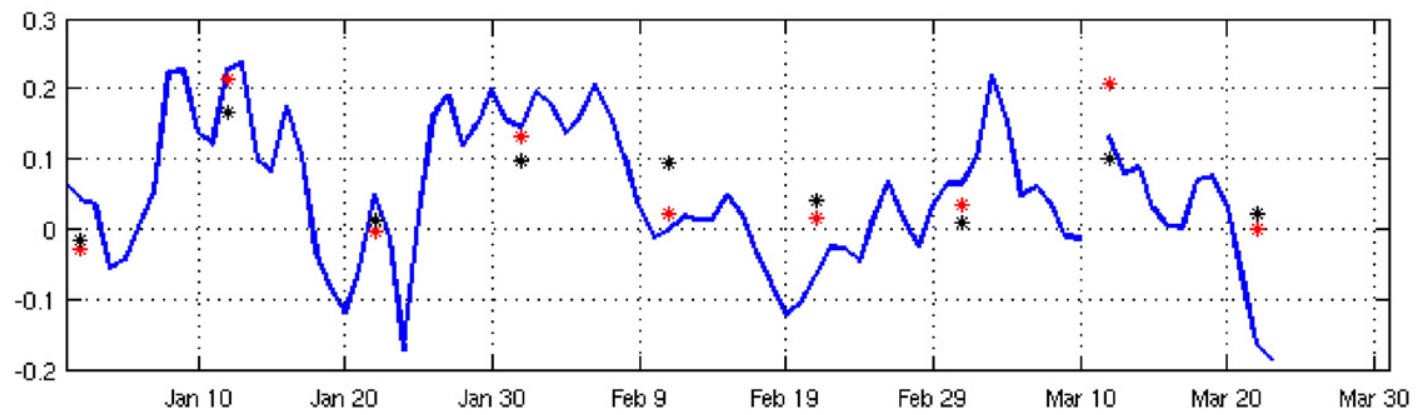

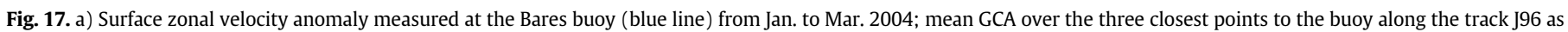

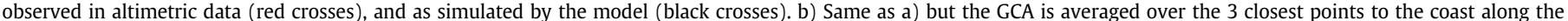

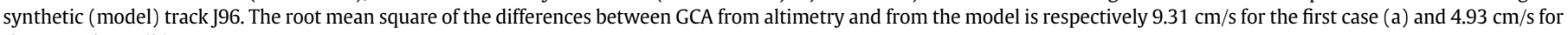
the second one (b).

Note that at a given date, altimetric data provides a unidirectional measure of the geostrophic velocity which limits the interpretation of some characteristics of the observed signal (e.g. variations of GCA from one track to the next), since the flow varies depending on topography and time.

The simulation is very helpful to better understand and evaluate the information contained in altimetric signal. We have first checked that the simulated surface fields were consistent with the buoy observations. We have then analysed the subsurface temperature and current fields in order to interpret the surface signal. The eastward surface currents are associated in the simulation with subsurface currents, clearly identified at $120 \mathrm{~m}$, that can extend down to $200 \mathrm{~m}$. The occurrences of the eastward pulses are well correlated with warm inflows. However, we have observed periods where the SST signature along the Spanish coast persists while the surface current has vanished. Finally the analysis of the wind and temperature and current conditions at the southern open-boundary tends to confirm the interpretation of the eastward pulses as the signature of the IPC, mostly established during northeastward wind conditions. Local winds on the northern Iberian coast also seem to have a significant influence on the current variability. Eastward winds intensify or favour the spreading of the slope current spread along the northern Spanish coast, whereas westward winds tend to weaken it.

In this study we evaluate a tool that is rarely used for the study of high frequency variations in coastal currents. Altimetric data are usually filtered, interpolated or averaged in space or time. Here, we have analysed individual passes without doing any averaging or time filtering. As a result we have faced new difficulties and inconsistencies, such as differences observed between consecutive or crossing tracks. We suggest that they are partly due to errors in the geophysical corrections applied to altimetric measurements. However, one of the major advantages of altimetry, compared to other remote sensing products such as infra-red SST imagery, is that altimetric data are available independently of the meteorological conditions. This property is of great importance in a region as cloudy as the Bay of Biscay in winter. We have seen the case of an eastward flow occurrence in October 2004 without any SST signature, whereas surface current data at the buoys and subsurface temperature and velocity fields in the model led to a clear identification of a slope current with warm anomalies. Anomalous eastward current signals were evident during the same period in altimetric data. We therefore suggest that the usual indices of detection of the IPC based solely on infrared SST images may be insufficient to reveal and monitor its high-frequency variability.

The analysis of along-track coastal signals at short-time scales as we made it in this study remains at the edge of what is achievable with the current datasets; a similar conclusion was reached by Vignudelli et al. (2005) from T/P data in the Mediterranean Sea. Data processing for coastal altimetric products is expected to evolve due to new studies on specific issues (e.g. wet tropospheric corrections) and to 'validation' studies in specific areas such as ours. We believe that one of the next challenges lies in the characterization of the uncertainties in the geophysical corrections and of their impact on geostrophic circulation estimates. SLA spatial filtering and deconvolution of noise and dynamical patterns are also complicated issues for small-scale signals. Following recent studies within $\mathrm{CTOH}$ (Birol and Dussurget, pers. comm., 2011) and users' feedback such as ours, some choices and strategy on data processing (e.g. spatial filtering) are evolving and will be different for future XTRACK products. In particular, future altimetric studies could be based on higher along-track resolution data in order to investigate further the details of the spatial structure of the current. Such high-resolution products remain very exploratory in terms of data and correction processing and still demand considerable effort for calibration and analysis techniques. 


\section{Acknowledgements}

Altimetric data used in this study are developed, validated, and distributed by the CTOH/LEGOS, France (http://ctoh.legos.obs-mip.fr/). Special thanks to F. Birol, R. Dussurget and M. Cancet (CTOH) for many interesting and useful discussions about this data set. Many thanks to Puertos del Estado for data at the Cabo Silleiro, Cabo de Peñas, Villano Sisargas and Estaca de Bares buoys. AVHRR (pathfinder, version 5) and MODIS SST images are processed and distributed by NASA Jet Propulsion Laboratory (JPL) via the PO.DAAC Ocean ESIP Tool (POET; http://poet.jpl. nasa.gov). The SST CMS dataset from the Centre de Météorologie Spatiale de Météo-France has been retrieved from the IFREMER ftp website (ftp.ifremer.fr/ifremer/cms/data/analyzed_sst/). We are very grateful to B. Le Cann and Nick Hall for helpful remarks on the manuscript. Many thanks to M. Le Hénaff for helpful discussions at the early stage of this work. We thank the two anonymous reviewers for their constructive remarks. This work is a contribution to the French EPIGRAM project on the Bay of Biscay funded by ANR-BLAN-08-0330_01 and LEFE/INSU/ CNRS. G. Herbert PhD's grant is provided by the French ministry of research and education. Support from the Centre National d'Etudes Spatiales through the OST project 'Multisensor Impact assessment in Coastal and Shelf Seas', from the Centre National de la Recherche Scientifique (CNRS) and from the Institut des Sciences de l'Univers (INSU) is acknowledged.

\section{Appendix A. Impact of the inclination of altimetry tracks on the zonal current estimate}

The impact of the inclination of the tracks on the estimates of the zonal along-shore current is assessed here using the simulation. We first compute the average of the geostrophic velocity anomalies over the three closest points to the Peñas and Bares buoys along the synthetic tracks. We then repeat the calculation for two other virtual tracks in the simulation presenting a strict north-south direction and each intercepting the coast at a buoy location (Fig. 16, blue line). The geostrophic velocities estimated from the SLA along these two tracks are therefore strictly zonal. The comparison between the averaged velocities from the inclined tracks and from the track perpendicular to the coast shows that the inclination of the altimetric tracks with respect to the north-south direction is small enough for the differences between the velocity estimates to be small. The differences can reach 5 to $10 \mathrm{~cm} / \mathrm{s}$ at specific dates and can be negligible at other dates when the real current is mostly zonal. However, the simulation suggests that these differences cannot explain the discrepancies between altimetric GCA and the surface zonal current at the buoy. The difference of inclination between the tracks of Jason1 and of TOPEX/ Poseidon does not induce misfits that are large enough to explain the differences that we observe at cross-over points in the altimetric data.

\section{References}

Alvarez-Fanjul, E., Alfonso, M., Ruiz, M.I., Lopez, J.D., Rodriguez, I., 2003. The Deep Water Network, In: Dahlin, H. (Ed.), 69th ed. Building the European Capacity in Operational Oceanography, vol. 445. Elsevier, New York, pp. 398-402.

Andersen, O.B., Scharroo, R., 2010. Range and Geophysical Corrections in Coastal Regions and Implications for Mean sea Surface Determination. In: Vignudelli, S., et al. (Ed.), Coastal Altimetry. Springer-Verlag, Berlin Heidelberg, pp. 103-145. doi:10.1007/978-3-642-12796-0_5.

AVELMOR, 2002. Développement d'une Analyse de Température de Surface de la mer à Échelle Fine au Centre de Météorologie Spatiale de Météo-France. Rapport final, 91 pp.

AVISO, 1996. Handbook for Merged TOPEX/POSEIDON Products, AVI-NT-02-101-CN, Edition 3.0.

Birol, F., Cancet, M., Estournel, C., 2010. Aspects of the seasonal variability of the Northern Current (NW Mediterranean Sea) observed by altimetry. Journal of Marine Systems 81297-81311.

Caballero, A., Pascual, A., Dibarboure, G., Espino, M., 2008. Sea level eddy kinetic energy variability in the Bay of Biscay, inferred from satellite altimeter data. Journal of Marine Systems 72, 116-134. doi:10.1016/j.jmarsys.2007.03.011.

Carrère, L., Lyard, F., 2003. Modelling the barotropic response of the global ocean to atmospheric wind and pressure forcing - comparisons with observations. Geophysical Research Letters 30 (6), 1275.
Chambers, D.P., Hayes, S.A., Ries, J.C., Urban, T.J., 2003. New TOPEX sea state bias models and their effect on global mean sea level. Journal of Geophysical Research 108 (C10), 3305. doi:10.1029/2003JC001839.

Cipollini, P., et al., 2010. The Role of Altimetry in Coastal Observing Systems. In: Hall, J. Harrison, D.E., Stammer, D. (Eds.), Proceedings of OceanObs'09: Sustained Ocean Observations and Information for Society, Vol. 2. ESA Publication WPP-306, Venice, Italy. 21-25 September 2009.

Coelho, H.S., Neves, R.R., Leitao, P.C., Martins, H., Santos, A.P., 1999. The slope current along the western European margin: a numerical investigation. Boletin del Instituto Espanol de oceanografia 15 (1-4), 61-72.

Frouin, R., Fuiza, A.F., Ambar, I., Boyd, T.J., 1990. Observations of a Poleward Surface Current off the coasts of Portugal and Spain during the winter. Journal of Geophysical Research 95, 679-691.

Garcia-Soto, C., PingreE, R., Valdés, L., 2002. Navidad development in the southern Bay of Biscay: climate change and swoddy structure from remote sensing and in-situ measurements. Journal of Geophysical Research 107 (C8). doi:10.1029/2001JC001012.

Gaspar, P., Grégoris, Y., Lefevre, J.-M., 1990. A simple eddy kinetic energy model for simulations of the oceanic vertical mixing: tests at station papa and long-term upper ocean study site. Journal of Geophysical Research 95 (C9), 16,179-16,193. doi:10.1029/JC095iC09p16179.

Gaspar, P., Ogor, F., Le Traon, P.-Y., Zanife, O.-Z., 1994. Estimating the sea state bias of the TOPEX and POSEIDON altimetres from crossover differences. Journal of Geophysical Research 99 (C12), 24,981-24,994. doi:10.1029/94JC01430.

Haynes, R., Barton, E.D., 1990. A poleward flow along the Atlantic coast of the Iberian Peninsula. Journal of Geophysical Research 95, 11425-11441.

Huthnance, J.M., 1984. Slope currents and "JEBAR”. Journal of Physical Oceanography $14,795-810$.

Large, W.G., Yeager, S.G., 2004. Diurnal to Decadal Global Forcing for Ocean and Sea-ice Models: The Data Sets and Flux Climatologies. Technical Report TN-460+STR NCAR. 105 pp.

Le Cann, B., Serpette, A., 2009. Intense warm and saline upper ocean inflow in the southern Bay of Biscay in autumn-winter 2006-2007. Continental Shelf Research 29, 1014-1025. doi:10.1016/j.csr.2008.11.015.

Le Hénaff, M., 2008. Évaluation objective de réseaux d'observation en domaine côtier par la modélisation d'ensemble, PhD Thesis, Univ. of Toulouse.

Le Hénaff, M., Roblou, L., Bouffard, J., 2010. Characterizing the Navidad current interannual variability using coastal altimetry. Ocean Dynamics. doi:10.1007/s10236-010-0360-9.

Lyard, F., Lefevre, F., Letellier, T., Francis, O., 2006. Modelling the global ocean tides: modern insights from FES2004. Ocean Dynamics 56, 394-415. doi:10.1007/s10236-006-0086-X.

Marsaleix, P., Auclair, F., Floor, J.W., Herrmann, M.J., Estournel, C., Pairaud, I., Ulses, C., 2008. Energy conservation issues in sigma-coordinate free-surface ocean models. Ocean Modelling 20, 61-89.

Marsaleix, P., Auclair, F., Estournel, C., 2009. Low-order pressure gradient schemes in sigma coordinate models: the seamount test revisited. Ocean Modelling 30 169-177.

Obligis, E., Desportes, C., Eymard, L., Fernades, L., Lazaro, C., Nunes, A., 2010. Tropospheric Corrections for Coastal Altimetry. In: Vignudelli, S., et al. (Ed.), Coastal Altimetry. Springer-Verlag, Berlin Heidelberg, pp. 147-175. doi:10.1007/978-3-642-12796-0_5.

Otero, P., Ruiz-Villarreal, M., 2008. Wind forcing of the coastal circulation off north and northwest Iberia: Comparison of atmospheric models. Journal of Geophysical Research 113, C10019. doi:10.1029/2008JC004740.

Otero, P., Ruiz-Villarreal, M., Peliz, A., 2008. Variability of river plumes off Northwest Iberia in response to wind events. Journal of Marine systems 72, 238-255.

Pairaud, I.L., Lyard, F., Auclair, F., Letellier, T., Marsaleix, P., 2008. Dynamics of the semidiurnal and quarter-diurnal internal tides in the Bay of Biscay. Part 1: barotropic tides. Continental Shelf Research 28, 1294-1315. doi:10.1016/j.csr.2008.03.004.

Peliz, A., Dubert, J., Haidvogel, D.B., Le Cann, B., 2003. Generation and unstable evolution of a density-driven Eastern Poleward Current: the Iberian Poleward Current Journal of Geophysical Research 108 (C8), 3268. doi:10.1029/2002JC001443.

Pichon, A., Corréard, S., 2006. Inertial tides modelling in the Bay of Biscay. Comparisons with observations. Scienta Marina, Oceanography of the Bay of Biscay 70S1, 65-88.

Pingree, R.D., Le Cann, B., 1989. Celtic and Armorican slope and shelf residual currents Progress in Oceanography 23, 303-338.

Pingree, R.D., Le Cann, B., 1990. Structure, strength and seasonality of the slope currents in the Bay of Biscay region. Journal of the Marine Biological Association of the United Kingdom 70, 857-885.

Pingree, R.D., Le Cann, B., 1992. Anticyclonic eddy X91 in the Southern Bay of Biscay, May 1991 to February 1992. Journal of Geosphysical Research 97 (C9), 14,353-14,367.

Reffray, G., Levier, B., Marsaleix, P., Lazure, P., Garnier, V., 2008. Intercomparaison de Modèles sur le Golfe de Gascogne Pour l'année 2004. Rapport d'activités MERCATOR-Océan. . 99 pp.

Roblou, L., Lamouroux, J., Bouffard, J., Lyard, F., Le Hénaff, M., Lombard, A., Marsaleix, P., De Mey, P., Birol, F., 2010. Post-Processing Altimeter Data Toward Coastal Applications and Integration into Coastal Models. In: Vignudelli, S., et al. (Ed.), Coastal Altimetry. Springer-Verlag, Berlin Heidelberg, pp. 217-246. doi:10.1007/978-3-642-12796-0_5.

Torres, R., Barton, E.D., 2006. Onset and development of the Iberian poleward flow along the Galician coast. Continental Shelf Research 26, 1134-1153.

Van Haken, H.M., 2002. Surface currents in the Bay of Biscay as observed with drifters between 1995 and 1999. Deep-Sea Research Part I 49, 1071-1086.

Vignudelli, S., Cipollini, P., Roblou, L., Lyard, F., Gasparini, G.P., Manzella, G., Astraldi, M. 2005. Improved satellite altimetry in coastal systems: case study of the Corsica Channel (Mediterranean Sea). Geophysical Research Letters 32, L07608.

Wahr, J.M., 1985. Deformation induced by polar motion. Journal of Geophysical Research 90 (B11), 9363-9368. 